IZA DP No. 8502

Relative Concerns for Consumption at the Top: An Intertemporal Analysis for the UK

Climent Quintana-Domeque

Johannes Wohlfart

September 2014

Forschungsinstitut zur Zukunft der Arbeit Institute for the Study of Labor 


\title{
Relative Concerns for Consumption at the Top: An Intertemporal Analysis for the UK
}

\author{
Climent Quintana-Domeque \\ University of Oxford \\ and IZA
}

Johannes Wohlfart

European Central Bank

\section{Discussion Paper No. 8502 \\ September 2014}

\author{
IZA \\ P.O. Box 7240 \\ 53072 Bonn \\ Germany \\ Phone: +49-228-3894-0 \\ Fax: +49-228-3894-180 \\ E-mail: iza@iza.org
}

\begin{abstract}
Any opinions expressed here are those of the author(s) and not those of IZA. Research published in this series may include views on policy, but the institute itself takes no institutional policy positions. The IZA research network is committed to the IZA Guiding Principles of Research Integrity.

The Institute for the Study of Labor (IZA) in Bonn is a local and virtual international research center and a place of communication between science, politics and business. IZA is an independent nonprofit organization supported by Deutsche Post Foundation. The center is associated with the University of Bonn and offers a stimulating research environment through its international network, workshops and conferences, data service, project support, research visits and doctoral program. IZA engages in (i) original and internationally competitive research in all fields of labor economics, (ii) development of policy concepts, and (iii) dissemination of research results and concepts to the interested public.
\end{abstract}

IZA Discussion Papers often represent preliminary work and are circulated to encourage discussion. Citation of such a paper should account for its provisional character. A revised version may be available directly from the author. 
IZA Discussion Paper No. 8502

September 2014

\section{ABSTRACT \\ Relative Concerns for Consumption at the Top: An Intertemporal Analysis for the UK}

This paper investigates whether the consumption of rich households provides a reference point in the consumption choices of non-rich households from an intertemporal perspective. Using UK household data on food consumption, we estimate the Euler equation implied by a life-cycle model incorporating relative concerns for the consumption of rich households. According to both our OLS and GMM estimates, for the population of non-rich individuals as a whole, there is no evidence of such relative concerns. These results are robust to alternative definitions of the reference group, the presence of exogenous effects and liquidity constraints, and the interval censoring nature of our food consumption data. However, we find some (correlational) evidence of heterogeneous effects across county and household characteristics, which is robust to simultaneous estimation. In particular, there are relative concerns (for consumption at the top) in counties with relatively low income inequality or relatively high population density. Households whose head has relatively low educational attainment are also subject to relative concerns for consumption at the top.

JEL Classification: D12, D91

Keywords: $\quad$ keeping up with the Joneses, inequality, trickle-down consumption, UK

Corresponding author:

Climent Quintana-Domeque

University of Oxford

Department of Economics

Manor Road Building

Manor Road

Oxford OX1 3UQ

United Kingdom

E-mail: climent.quintanadomeque@economics.ox.ac.uk

\footnotetext{
${ }^{*}$ We would like to thank Tony Atkinson for his helpful comments and suggestions. We also thank Alexis Grigorieff, Leander Heldring, Michael Koelle, Lu Liu, Salvatore Morelli and Christopher Roth for helpful discussions. Any errors contained in the paper are our own. The views contained here are those of the authors and not necessarily those of their respective institutions.
} 


\section{Introduction}

Over the last three decades, income inequality has increased substantially in Englishspeaking countries and, to a smaller extent, in continental European countries and Japan. Specifically, incomes at the top of the distribution continued to grow while incomes in the middle and at the bottom almost stagnated (Atkinson et al., 2011; Piketty, 2014). While this shift is commonly regarded as problematic, a range of questions is still not well-understood: What are the exact channels through which inequality affects welfare? Does inequality contribute to shaping other economic outcomes? What is the magnitude of such effects?

This paper explores a potential mechanism through which income inequality affects welfare and economic outcomes: Reference-dependent preferences in consumption. A growing body of empirical literature provides evidence for the importance of relative concerns in consumption choices (Kuhn et al., 2011; De Giorgi et al., 2012; Lewbel et al., 2013). Models of relative concerns usually assume that utility depends both on own consumption and on how own consumption compares to the average consumption among all others in a consumer's reference group. Here we take a different approach: We investigate whether the consumption of households at the top of the income distribution provides a reference point in the consumption choices of those not at the top of the distribution. We label this form of relative concerns "relative concerns for consumption at the top". Using household data from the UK, we examine potential effects of such relative concerns on the intertemporal allocation of expenditure. ${ }^{1}$

Relative concerns for the consumption of rich households among non-rich households have a range of important implications. First, they provide a channel through which inequality affects welfare. Their effects will be most important when income growth concentrates at the top, as it has been the case in recent decades. In this regard, the UK provides an interesting case to study the implications of upwardlooking relative concerns in consumption. Figure 1 displays the evolution of average incomes in the UK since 1980 until 2011 for the top 5\%, the top 10\% and the bottom

\footnotetext{
${ }^{1}$ Throughout the analysis, we use the terms "consumption", "expenditure" and "spending" interchangeably. Since we focus on food consumption, spending and consumption should be closely aligned.
} 
90\%. The annual percentage growth rate of average income between 1990 and 2011 has been $1.04 \%$ for the top $5 \%, 0.83 \%$ for the top $10 \%$ and $0.51 \%$ for the bottom 90\%. This development has made the UK the most inegalitarian among European countries (Piketty, 2014, p.325). ${ }^{2}$ With relative concerns for the consumption of rich households, non-rich households derive a utility loss from observing higher and higher consumption of their rich peers. ${ }^{3}$ Second, relative concerns for the consumption of rich households imply that income inequality contributes to shaping the consumption behaviour of non-rich households. This links inequality to a range of other policyrelevant topics such as debt behaviour or the design of optimal fiscal and monetary policy (Airaudo and Bossi, 2014). Beyond the effects of inequality, one could think of implications for the transmission of uninsured shocks hitting households at the top of the income distribution (De Giorgi et al., 2012, p.3) or for the welfare effects of residential sorting by income (Luttmer, 2005, p.964).

The idea that lower income classes seek to emulate the spending patterns of the rich goes back to Veblen (1899) and was first formalised as the "Relative Income Hypothesis" by Duesenberry (1949). More recently, a number of studies argued that increasing top income shares were partly responsible for the decline in savings rates among middle-class households in the US. Bertrand and Morse (2013), using data from the Consumer Expenditure Survey (CEX), provide evidence that higher income and consumption among rich households have induced non-rich households to consume a larger fraction of their income. Frank et al. (2010) suggest that households compare their consumption with the consumption of households that are located slightly higher in the distribution of income. In their model, an increase in income and consumption at the top can generate "expenditure cascades" that ripple all the way through the income distribution. In combination with improved credit availability, such mechanisms have even been quoted as a contributing factor to the 2008 financial crisis (Rajan, 2010).

A potential weakness of these lines of argument is that they rely on a certain

\footnotetext{
${ }^{2}$ The increasing dispersion of real incomes was largely driven by an increase in wage inequality, amongst others originating from higher pay in the financial sector (Blundell and Etheridge, 2010; Bell and Van Reenen, 2013).

3 This provides an explanation for the negative relationship between inequality and happiness that has been documented empirically (Easterlin, 1974; Alesina et al., 2004).
} 
degree of myopia among consumers. The intertemporal budget constraint implies that spending more today to get closer to the consumption of higher income classes entails lower relative consumption in the future. If consumers recognise that relative standing will also matter to them in the future, it is not obvious that higher spending among rich households will induce them to consume a larger fraction of their permanent income (Arrow and Dasgupta, 2009). In this paper, we explore the effects of relative concerns for the consumption of rich households on intertemporal consumption choices of forward-looking non-rich households. With this goal in mind, we outline a life-cycle model along the lines of Galí (1994). In this model, non-rich households compare their overall level of expenditure with the expenditure of rich households. The Euler equation arising out of the model implies that non-rich households aim to smooth their consumption relative to the average consumption of rich households in their reference group. Importantly, households in this model recognise that increasing consumption levels to achieve higher relative consumption today would ultimately lead to lower relative consumption in the future. Instead, by adjusting their consumption growth non-rich households are able to spread the utility loss that derives from higher consumption among rich households optimally over time.

We estimate the Euler equation using data on food consumption from the British Household Panel Survey (BHPS) and data on earnings distributions from the Annual Survey of Hours and Earnings (ASHE) over the period 1997-2008. Households are classified into rich and non-rich according to the position of the main earner in the county-level earnings distribution. Several concerns arise at the time of estimating the effects of the growth of consumption among the rich on consumption growth of the non-rich: How to define the reference group? How to deal with the so-called reflection problem? We start by constructing the reference point for a given non-rich household as the average consumption among rich households in its county of residence, but we also experiment with a definition that includes demographic characteristics as well. Regarding the reflection problem, we note that households in a given county might share similar unobserved characteristics and may be exposed to common shocks, giving rise to spurious correlation in consumption outcomes (Manski, 1993). We try to address this concern by specifying a county-specific discount factor and using 
GMM estimation based on orthogonality conditions of the model. ${ }^{4}$

We find no evidence for an effect of the growth in rich consumption on the consumption growth of non-rich households, at least for the population of nonrich households as a whole. Both OLS and GMM estimates of the Euler equation yield small positive coefficient estimates that are close to zero and not statistically significant. These findings are robust to alternative definitions of the reference group, the presence of exogenous effects and liquidity constraints, and the interval censoring nature of our food consumption data. We also examine whether there are heterogeneous effects across county and household characteristics. In particular, we find some (correlational) evidence of relative concerns (for consumption at the top) in counties with relatively low income inequality -consistent with the idea that non-rich households in low inequality areas are more likely to compare themselves to their rich co-residents- or relatively high population density -consistent with the idea that consumption as signal for status will have a more prominent role if social interactions are more anonymous. Households whose head has relatively low educational attainment are also subject to relative concerns for consumption at the top, which is consistent with a trade-off between conspicuous consumption and human capital as signals for unobserved income (Moav and Neeman, 2012). The presence of these heterogeneous effects is robust to simultaneous estimation.

Besides extending the literature on relative concerns for the consumption of the rich, we contribute to the empirical micro literature on relative concerns in consumption more generally. Among others, the effect of relative concerns on the intertemporal allocation of expenditure has been examined by Ravina (2007). Using a Californian data set on credit card purchases, she estimates that an increase in the growth of city-level consumption by 1 percentage point increases own consumption growth by 0.2 percentage points. Alvarez-Cuadrado et al. (2012) use data from the Spanish Household Budget Continuous Survey (ECPF) to estimate an Euler equation that incorporates relative concerns. They provide evidence for an effect of the consumption growth of neighbouring households on own consumption growth in a similar range. Maurer and Meier (2008) exploit a social equilibrium condition

\footnotetext{
${ }^{4}$ We instrument the growth in rich consumption with lagged variables, since under rational expectations the forecast error will be uncorrelated with all the available information in the prior year.
} 
to identify peer effects and estimate their model on food consumption data from the US Panel Study of Income Dynamics (PSID). Applying a definition of reference groups along demographic dimensions, they find evidence for moderate peer effects in consumption growth. ${ }^{5}$ Whereas all of these studies (including those with an intratemporal focus) assume that relative concerns apply uniformly to the consumption of all others in someone's reference group, our paper concentrates on relative concerns for the consumption of the rich.

The remainder of this paper is structured as follows. Section 2 outlines a model of "keeping up with the 'rich' Joneses" in which non-rich households compare their consumption to the consumption of rich households in their reference group. Section 3 discusses the data and the methodology. Section 4 presents the results of the estimation of the Euler equation. Section 5 contains several robustness checks. Section 6 concludes.

\section{A model of "keeping up with the 'rich' Joneses"}

This section outlines a model of "keeping up with the 'rich' Joneses" in which non-rich households compare their consumption with the consumption of rich households in their reference group. Its derivations follow closely Maurer and Meier (2008) and Alvarez-Cuadrado et al. (2012).

There are several reasons why "non-rich" (middle and low income) households could have relative concerns for the consumption of the "rich" (those with higher incomes). Perhaps one of the most well-known argued reasons for the presence of upward-looking relative concerns is that consumers may want to emulate the spending habits of the upper classes to signal status. This idea goes back at least to Veblen (1899, p.104) who noted that "in any community where class distinctions

\footnotetext{
${ }^{5}$ A range of studies have examined peer effects in intratemporal consumption choices. Using Dutch household data, Alessie and Kapteyn (1991) estimate an almost-ideal demand system that incorporates good-specific relative concerns. Kapteyn et al. (1997) conduct a similar exercise in the context of a Linear Expenditure System. Both of these studies apply a demographic definition of reference groups and find evidence for good-specific relative concerns. More recently, Lewbel et al. (2013) model peer effects as affecting fixed costs that have to be incurred to derive any utility at all. Estimating their model with Indian household data, they find important peer effects in the consumption of visible goods among households with similar demographic characteristics. We examine potential effects of relative concerns for the consumption of rich households on the intratemporal allocation of expenditure in the robustness checks section of the paper.
} 
are somewhat vague, all canons of reputability and decency, and all standards of consumption, are traced back by insensible gradations to the usages and habits of thought of the highest social and pecuniary class - the wealthy leisure class." While individuals may directly derive utility from a high social standing, the imitation of the spending of the rich could also be instrumental to other goals such as success in the competition for marriage partners or professional success. In addition, empirical evidence from the happiness literature suggests that comparisons appear to be mostly upward: Having low relative standing negatively affects satisfaction, but individuals do not derive much satisfaction from a high relative position (Ferrer-i Carbonell, 2005; Senik, 2009; Card et al., 2012).

How do relative concerns for the consumption of rich households influence the intertemporal consumption choices of non-rich households? A life-cycle model along the lines of Galí (1994) gives testable implications of such preferences for consumption growth. Throughout, we assume that utility is additively time-separable, separable between consumption of non-durable and durable goods and separable between non-durable consumption and leisure. ${ }^{6}$ Moreover, we abstract from finite lives of households and the possibility of liquidity constraints or precautionary motives. When taking the model to the data, therefore, we will try to focus on non-liquidity constrained households. We assume that each household acts as a single decisionmaking unit, so that the household utility function is independent of prices and income. ${ }^{7}$ At the beginning of each period, non-rich household $i$ with rational expectations solves the following optimisation program:

$$
\begin{aligned}
\max _{C_{i, t+j}, A_{i, t+j+1}} U_{t} & =E_{t} \sum_{j=0}^{\infty} \beta^{j} u\left(C_{i, t+j}, G E O M\left[C_{i, t+j}^{R}\right], \psi_{i, t+j}\right) \\
\text { s.t. } \quad A_{i, t+j+1} & =\left(1+r_{i, t+j}\right) A_{i, t+j}+Y_{i, t+j}-C_{i, t+j},
\end{aligned}
$$

where $C$ is overall non-durable consumption, $A$ denotes the real (net) wealth or (net) assets, $Y$ is real household income, $\beta$ is the discount factor, $U_{t}$ is the discounted

\footnotetext{
6 This last separability assumption allows us to abstract from the labour choice.

${ }^{7}$ Technically, we are assuming that the Pareto weight of each individual felicity function in the household utility function is constant (Browning et al., 2014).
} 
stream of expected future utility at time $t, u$ is the intra-period sub-utility function, $r_{i, t+j}$ is the real ex-post interest rate that the household $i$ faces, which is unknown at the beginning of period $t+j$, and $\psi_{i, t+j}$ is a vector of taste shifters, such as age and the number of children in the household. Finally, GEOM $\left[C_{i, t+j}^{R}\right]$ denotes the geometric mean of the consumption of rich households in household $i$ 's reference group at time $t+j .{ }^{8}$ The optimisation problem implies the first order condition:

$$
E_{t-1}\left[\beta\left(1+r_{i, t}\right) \frac{\partial u / \partial C_{i, t}}{\partial u / \partial C_{i, t-1}}\right]=1 .
$$

In order to derive a closed form solution for consumption growth, it is necessary to assume a particular form for the intra-period sub-utility function. We adopt a version of the function suggested in Abel (1990) and widely used in the literature ever since (Dynan, 2000; Ravina, 2007; Alvarez-Cuadrado et al., 2012). Specifically, we assume that the household exhibits constant relative risk aversion (CRRA) -consistent with the available empirical evidence (Chiappori and Paiella, 2011)- and its preferences can be described through the isoelastic intra-period sub-utility function:

$$
\begin{aligned}
u\left(\tilde{C}_{i, t+j}, \psi_{i, t+j}\right) & =\exp \left(\psi_{i, t+j}\right) \frac{\tilde{C}_{i, t+j}^{1-\rho}}{1-\rho} \\
\text { where } \quad \tilde{C}_{t+j} & =\frac{C_{t+j}}{\left(G E O M\left[C_{i, t+j}^{R}\right]\right)^{\gamma}} .
\end{aligned}
$$

$\rho$ denotes the coefficient of relative risk aversion or the inverse of the intertemporal elasticity of substitution. The parameter $\gamma$ can be interpreted as the strength of the relative concern for consumption of rich households and its estimation is the focus of this paper. Hence, the model nests the standard life-cycle model (i.e., without relative concerns) using the CRRA utility function -which is standard in the estimation of Euler equations (Attanasio et al., 1999; Alan et al., 2009)- for the case $\gamma=0$. The Euler equation (2) can now be written as:

\footnotetext{
${ }^{8}$ The formulation using the geometric mean is chosen because it yields an empirical specification with the arithmetic mean of log consumption in the reference group as independent variable. This specification is more robust to outliers than the one obtained using the arithmetic mean in the utility function.
} 


$$
\beta E_{t-1}\left[\left(1+r_{i, t}\right) \exp \left(\Delta \psi_{i, t}\right)\left(\frac{\tilde{C}_{i, t}}{\tilde{C}_{i, t-1}}\right)^{-\rho}\right]=1
$$

Taking a log-linear approximation around a steady state, in which variables are either constant or grow at a constant rate, and ignoring the residual non-log-linear component of consumption growth, one obtains the expression:

$$
E_{t-1}\left[\Delta \ln \tilde{C}_{i, t}\right]=\frac{1}{\rho} \ln \beta+\frac{1}{\rho} E_{t-1}\left[\ln \left(1+r_{i, t}\right)\right]+\frac{1}{\rho} E_{t-1}\left[\Delta \psi_{i, t}\right]
$$

A detailed derivation of this expression is given in section A.1 in the Appendix. Letting $\tilde{C}_{t}=\frac{C_{t}}{\left(G E O M\left[C_{i, t}^{R}\right]\right)^{\gamma}}$ and using the fact that the geometric mean of the $\log$ equals the log of the arithmetic mean, equation (4) can be rewritten as:

$$
\begin{aligned}
E_{t-1}\left[\Delta \ln C_{i, t}\right] & =\frac{1}{\rho} \ln \beta+\frac{1}{\rho} E_{t-1}\left[\ln \left(1+r_{i, t}\right)\right] \\
& +\frac{1}{\rho} E_{t-1}\left[\Delta \psi_{i, t}\right]+\gamma E_{t-1}\left[\Delta A R I T M\left[\ln C_{i, t}^{R}\right]\right],
\end{aligned}
$$

where ARITM $\left[\ln C_{i, t}^{R}\right]$ denotes the arithmetic mean of $\log$ consumption among the rich households in non-rich household $i$ 's reference group. ${ }^{9}$ This implies for observed consumption growth at time $t$ :

$$
\Delta \ln C_{i, t}=\frac{1}{\rho} \ln \beta+\frac{1}{\rho} \ln \left(1+r_{i, t}\right)+\frac{1}{\rho} \Delta \psi_{i, t}+\gamma \Delta A R I T M\left[\ln C_{i, t}^{R}\right]+\epsilon_{i, t},
$$

where $E_{t-1}\left[\epsilon_{i, t}\right]=0$.

$\epsilon_{i, t}$ denotes the forecast error that reflects innovations to permanent income (Dynan, 2000, p.393). Under rational expectations the forecast error will be uncorrelated

\footnotetext{
${ }^{9}$ Alternatively, following Muellbauer (1988) and Dynan (2000), one could use the specification $\ln \tilde{C}_{i, t}=\ln \left(C_{i, t}-\gamma G E O M\left[C_{i, t}^{R}\right]\right)$ and approximate it with $\ln C_{i, t}-\gamma \ln G E O M\left[C_{i, t}^{R}\right]$, obtaining an equivalent expression.
} 
with all available information at time $t-1$. This insight will prove useful when addressing the reflection problem that arises from the fact that rich and non-rich households in a particular reference group may be subject to common shocks or share similar unobservable characteristics.

Remark. According to the Euler equation (5), non-rich households aim to smooth their consumption profile relative to the consumption of rich households. This does not imply that increasing consumption among rich households leads nonrich households to excessively increase their consumption levels as it is argued in Frank et al. (2010) or in Bertrand and Morse (2013). Indeed, households recognise that increasing consumption today to keep up with their rich neighbours would lead to lower relative consumption in the future. Non-rich households therefore smooth their consumption by adjusting their consumption growth. To illustrate this point, assume that non-rich households learn at time $t$ that the growth rate of the consumption of the rich at time $t+1$ increases by an amount $\Delta g$. Non-rich consumers will react by adopting a path with a lower initial consumption at time $t$ but a growth rate that is higher by an amount $\gamma \Delta g$. The initial reduction in consumption is necessary to satisfy the intertemporal budget constraint. In this way, forward-looking non-rich households are able to spread the utility loss that derives from higher spending among rich households optimally over time. The model outlined above differs from the standard model only in that it incorporates relative concerns. It is therefore a natural starting point to examine the importance of upward-looking relative concerns in consumption. Indeed, estimating equation (5) provides a direct test against a model without relative concerns.

\section{Data and methodology}

\subsection{Data from the BHPS}

Our main source of data is the British Household Panel Survey (BHPS), a nationally representative study that ran from 1991 until 2008. The initial sample consisted of some 5,500 households including about 10,300 individuals from England, Scotland and Wales. Additional samples added 1,000 low-income households in 1997, 1,500 
households from Scotland and Wales each in 1999, and 2,000 households from Northern Ireland in 2001. The main topics covered in the BHPS are housing, residential mobility, health behaviour, labour market behaviour, socio-economic values and income. ${ }^{10}$

While the BHPS has become the main survey used in studies on labour supply in the UK, it has been shown to be also a potentially valuable resource for analyses of consumption and savings (Guariglia and Rossi, 2002; Disney et al., 2010; Etheridge, 2012). The consumption items available in the BHPS are similar to the ones available in the US Panel Study of Income Dynamics (PSID), which has been widely used for studying consumption behaviour (Mankiw and Zeldes, 1991; Dynan, 2000; Alan et al., 2009). Specifically, the categories available in the BHPS are food consumed at home, food consumed away from home, the amount spent on leisure activities, utilities and a range of consumer durables. In line with a large part of the consumption literature, we focus on food consumption. That is, the measure of non-durable consumption that we use to estimate the Euler equation (5) is the sum of food consumed at home and food consumed at restaurants.

The question on expenditure on food consumed at home is asked at the household level and reads: "Please tell me approximately how much your household spends each week on food and groceries". Households are told that this includes "take-aways" eaten in, but excludes all meals eaten outside the home. In contrast, the question on food consumed away from home is asked at the individual level. Household members are asked: "Tell me about how much you personally spend in an average month on eating out at, or buying take-away food from a restaurant, pub or cafe, including school meals or meals at work?". Since "take-aways" eaten in are included in both questions, there might be a tiny overlap between the two categories. However, since this should concern only a small fraction of overall food expenditure, we do not expect this overlap to induce a large bias in our estimates.

The expenditures on each of the two categories are measured in 13 bands from $£ 0-£ 160 .{ }^{11}$ Following Guariglia and Rossi (2002) and Etheridge (2012), we assign

\footnotetext{
${ }^{10}$ For a detailed description of the BHPS, see Jenkins (2010).

${ }^{11}$ The categories are $£ 0, £ 0-£ 9, £ 10-£ 19, £ 20-£ 29, £ 30-£ 39, £ 40-£ 49, £ 50-£ 59, £ 60-$ $£ 79, £ 80-£ 99, £ 100-£ 119, £ 120-£ 139, £ 140-£ 159, £ 160$ and over. There are no zeros in food consumed at home.
} 
midpoints to all categories but the highest one, to which we assign $£ 180$. Since the width of the categories is increasing in the amount spent, this can be expected to induce additional measurement error that has an approximately multiplicative form. Etheridge (2012) provides a justification for this procedure. Using the PSID he estimates second moments of the distribution of consumption changes both using data concentrated at midpoints and untransformed data. He concludes that the procedure yields empirically accurate estimates. Nevertheless, to address the possibility of non-classical measurement error, we will check the robustness of our main estimates to accounting for interval censoring.

To construct a measure for household consumption, we scale the two categories to give yearly figures. We deflate them to 2000 prices by the CPI for food items and non-alcoholic beverages and the CPI for catering services (including restaurants, cafes and canteens), respectively. ${ }^{12}$ We then sum real expenditures on food consumed at restaurants across household members and add household consumption of food at home.

\subsection{Using food consumption as a measure for overall non- durable consumption}

In using food consumption as a measure for overall non-durable consumption we follow a long tradition in the literature (Hall and Mishkin, 1982; Zeldes, 1989; Runkle, 1991; Dynan, 2000; Maurer and Meier, 2008). However, this procedure has been chosen mainly due to lack of better panel data on consumption. In this subsection we comment on both its disadvantages and advantages.

Disadvantages. First, survey data on food consumption is particularly noisy. Alan et al. (2009, p.321) estimate that 62 percent of the variation in consumption growth in the PSID are due to noise. Consequently, hypothesis tests of parameter values using only food data may have a low power. We address the problem of measurement error by using GMM. Second, food consumption might behave fundamentally differently than overall non-durable consumption. For instance, basic food expenditure may respond only mildly to unexpected shocks to income (Shea,

\footnotetext{
${ }^{12}$ The source of the CPI data is the Office of National Statistics (ONS).
} 
1994). Following Ravina (2007) we check that our consumption measure exhibits the key features of overall consumption: a hump-shape over the life-cycle and a positive relationship with income. Figure 2 shows the fitted values of local polynomial regressions of total food consumption on age of the head of household and on net total household income. Reassuringly, our data on total food consumption match the key characteristics of overall consumption. Finally, estimating an Euler equation for a subcategory of consumption is only valid if one invokes additional separability assumptions. In our case, we need to assume that utility is separable between consumption of food and other consumption. This assumption would be violated if (for instance) the utility derived from eating at a nice restaurant varied with the amount spent on clothing (Dynan, 2000, p.401).

Advantages. There are some advantages of our consumption measure. For instance, estimating an Euler equation with expenditure data requires a measure of consumption with low durability, i.e. a measure for which consumption plausibly equals expenditure. This is likely to be the case for food. In other contributions, such as Ravina's (2007) study using credit card expenditure, part of the consumption measure might stem from spending on durable goods. Moreover, as argued in Maurer and Meier (2008, p.460), in the visibility survey conducted by Heffetz (2011) food consumption at home and at restaurants are ranked in the (upper) middle of the distribution across goods in terms of their visibility. ${ }^{13}$ Thus, our consumption measure seems to be a good proxy for overall consumption regarding its susceptibility to peer effects.

\subsection{Construction of the independent variables and study sample}

Choice of reference groups. As indicated by Manski (1993), inference in social interaction models is not possible unless the researcher has prior information on the composition of reference groups. Lacking direct survey questions on the composition of someone's social circle, there are two approaches commonly followed in the literature. The first one postulates that individuals compare themselves to other individuals

\footnotetext{
${ }^{13}$ Among 31 expenditure categories, food at restaurants is ranked 7 th and food at home is ranked 14 th in terms of visibility.
} 
living in the same geographical area (Blanchflower and Oswald, 2004; Luttmer, 2005; Ravina, 2007; Alvarez-Cuadrado et al., 2012). The second approach assumes that individuals compare themselves primarily to other individuals sharing certain demographic characteristics such as age, gender, education or profession (Alessie and Kapteyn, 1991; Maurer and Meier, 2008; Lewbel et al., 2013). In our main analysis, we follow the first approach and assume that a household's reference group consists of all other households living in the same county. Using this definition, we examine whether the consumption growth of "rich" households can explain the consumption growth of "non-rich" households within a given reference group. However, we will also investigate what happens when using a more specific reference group definition based not only on geographical considerations but on demographic characteristics as well.

Classification into rich and non-rich. Our research question calls for a classification of the households in our BHPS sample into rich and non-rich. In principle, one could attempt to estimate county-level income distributions out of the BHPS. However, the small number of observations in each cell as well as over- and under-sampling of particular income groups render such an exercise unreliable. This suggests that a larger, external source should be used to obtain the relevant percentiles of the county-level income distribution. The only such data source available for the UK is the Annual Survey of Hours and Earnings (ASHE). The ASHE collects data on earnings and working hours of a one percent representative sample of all individuals in paid employment in the UK, and the Office of National Statistics (ONS) publicly provides estimates of the deciles of workplace-based county-level earnings distributions. We use these estimates in our analysis.

To classify the households in our sample, we first identify the main earner in each household. ${ }^{14}$ In each county and year, a household is classified as rich if the current gross labour earnings of the main earner in his or her first job exceed the 80th

\footnotetext{
${ }^{14}$ Main earnings are defined as current gross labour earnings of the main earner in the household from his or her main job before taxes, National Insurance contributions and other deductions. We take the variables for current labour earnings and total household income in our BHPS sample from a supplementary dataset of derived income variables provided by researchers of the University of Essex. This dataset has been widely used in analyses using the BHPS (Blundell and Etheridge, 2010; Etheridge, 2012). All income variables refer to current income, are deflated by the CPI and are scaled to give an annual figure.
} 
percentile of the distribution of individual labour earnings from the ASHE. ${ }^{15}$ Arguably, the 80th percentile is a fairly generous definition of "rich" households. However, this choice represents a compromise between a narrow definition of rich households and having sufficient observations in the rich group to construct meaningful estimates of the mean "rich consumption" in a given county and year. In addition, by choosing this threshold, we can compare our findings to those in Bertrand and Morse (2013).

This classification of households into rich and non-rich has some shortcomings. First, it does not take into account total household income. As a result, households with a single earner whose earnings exceed the 80th percentile could be classified as rich while households with several earners whose individual earnings just fall short of the threshold could be classified as non-rich. However, it seems plausible that the position of the main earner is most relevant for comparison effects along the earnings distribution. Second, it neglects non-labour income such as capital and pension income. Given that the increase in income inequality in the UK was largely driven by an increase in wage inequality (Blundell and Etheridge, 2010), this should not be a major concern for our analysis. Third, the ASHE only provides information on the distribution of earnings of individuals in paid employment. However, we use the same threshold to classify households whose main earner is self-employed. Since the main reason for using the ASHE is to obtain a threshold that is invariant to the sampling variation of the BHPS, we do not consider this to be a severe problem.

Construction of the study sample. We use the 12 waves of the BHPS from 1997 until 2008 in line with the availability of the variable on food consumed away from home and of the earnings distribution data from the ASHE. Since ASHE data are not publicly available for Northern Ireland, we ignore the Northern Irish sample of the BHPS. The initial unbalanced panel of all English, Scottish and Welsh observations completing a full interview consists of 72,437 household-year observations from 13,813 households and 140 counties. Household years are matched across waves according to the identification number of the head of household, and households with head changes are treated as new households. Moreover, we treat households whose county of residence changes as new households. We cannot use the distribution of individual

\footnotetext{
${ }^{15}$ The 80th percentile of the county-level distribution of individual earnings from employee jobs includes all part-time and full-time jobs paid on adult rates and refers to gross pay before taxes, National Insurance contributions and other deductions.
} 
labour earnings to classify households who are retired or in full-time education, so we neglect these households in our analysis (22,244 household-year observations). We drop 351 observations with missing employment status of the head of household and trim the top and bottom 1 percent of the distribution of net disposable household income in each year to account for outliers (982 observations). Since our consumption data are categorised and we take midpoints, we do not have substantial outliers in our consumption variable. We therefore stay away from excluding outliers in this category. 829 observations are excluded due to missing consumption data. The resulting sample consists of 48,031 household-year observations living in 10,407 households and 140 counties.

We merge the deciles of the county-level earnings distributions from the ASHE to this sample and classify observations into "rich" or "non-rich" as explained above. Next, to obtain meaningful estimates of the mean log consumption among "rich" households, we restrict the analysis to county-year cells with at least 10 rich observations. While this number is still not very high, it again represents a compromise between having a sufficient number of rich households in each countyyear cell and keeping a fairly large number of counties in our analysis. We checked the robustness of our findings to using a broader definition of "rich" households. This led to a greater number of rich observations per cell and therefore less noisy estimates of their mean consumption. Our results remained very similar throughout. The remaining sample contains 28,746 observations (7,571 rich and 21,137 non-rich) residing in 62 counties. ${ }^{16}$ We estimate the mean (log) consumption of total food and the average log net disposable income in the rich group in each county-year cell that is part of this sample. ${ }^{17}$

Figure 3a shows the evolution of average consumption among rich and non-rich

\footnotetext{
${ }^{16}$ Table A1 in the appendix shows how the composition of our sample is affected by the sample selection. Columns 3 and 4 show summary statistics for rich and non-rich observations in the unrestricted sample, while columns 5 and 6 refer to the restricted sample with at least 10 rich observations in each cell. We conducted $t$-tests for differences in means between the restricted and unrestricted samples. The means differ significantly only for relative consumption of food at home and food at restaurants (for both rich and non-rich) and marital status and educational attainment above A-level (for non-rich). However, the economic magnitude of the differences is negligible, so the deletion of small cells should not be a major concern.

${ }^{17}$ Current household net disposable income refers to the sum of labour income, investment income, pension income and benefit income of all household members after taxes, National insurance contributions and other deductions. Its data source is the BHPS supplementary dataset of derived income variables.
} 
households over the sample period 1997-2008. Consumption levels peak in 2003 and 2004 and drop with the onset of the financial crisis. Figure 3b displays the evolution of the average 80-50 ratio and the average 90-50 ratio of county-level earnings distributions in our sample. Both numbers increase over the sample period. This indicates that not only national but also local inequality in the UK has grown. Thus, the focus on the county level seems appropriate to study the implications of increasing inequality in the UK. Figures $4 \mathrm{a}$ and $4 \mathrm{~b}$ reproduce the figures above but with separate scales for the two curves in each panel, so that similarities or differences are more obvious.

Because we aim to study how the consumption behaviour of non-rich households is affected by the consumption of rich households, we subsequently drop rich observations from our study sample. Moreover, in line with most of the consumption literature, we drop observations for which the age of the head is outside the range 20-64 (978 household-year observations). This focus can be justified by the fact that the consumption behaviour of such households is likely to follow different patterns, for instance due to health-related spending ("old" households) or liquidity constraints ("young" households). Since they represent only a fairly small fraction of our sample, we also drop 845 household-year observations whose head belongs to an ethnic minority. ${ }^{18}$ Moreover, we drop all observations with missing values in variables that are to be used across all estimations (404 observations due to missing employment status of the spouse). The resulting sample is an unbalanced panel consisting of 18,910 non-rich household-year observations living in 5,367 households and 62 counties. From this study sample, we select the samples used in the different sections based on the largest sample available given part-specific considerations, the set of variables used and the transformations made.

\footnotetext{
${ }^{18}$ One might be worried that observations in the rich group that were used to estimate the mean consumption of rich households were partly outside this age range and / or belonged to ethnic minorities, while our final study sample of non-rich households does not contain such observations. This choice was made to have a sufficient number of counties with at least 10 rich observations available while at the same time obtaining a meaningful sample for our main estimations. We checked the robustness of our results to excluding these households from the rich group. While the coefficients were less precisely estimated, their direction and magnitude remained very similar.
} 


\section{Results of the estimation of the Euler equation}

\subsection{Empirical strategy and sample selection}

Euler equation. The Euler equation implied by the model outlined in section 2 (equation (5)) describes the consumption growth of non-rich household $i$ at time $t$ and is given by:

$$
\Delta c_{i, t}=\frac{1}{\rho} \ln \beta+\frac{1}{\rho} \ln \left(1+r_{i, t}\right)+\frac{1}{\rho} \Delta \psi_{i, t}+\gamma \Delta \bar{c}_{i, t}^{R}+\epsilon_{i, t}
$$

where $\quad E_{t-1}\left[\epsilon_{i, t}\right]=0$.

$\Delta \bar{c}_{i, t}^{R}$ is the change in mean log consumption of the rich households living in non-rich household $i$ 's county of residence. For empirical fit it is necessary to let the growth rate of consumption depend on changes in preference shifters that are likely to affect the marginal utility of consumption (Attanasio, 1999). Therefore, we specify the vector of preference shifters according to:

$$
\begin{aligned}
\psi_{i, t} & =\alpha_{0 i}+\alpha_{1} \text { Age }_{i, t}+\alpha_{2} \text { Age }_{i, t}^{2}+\alpha_{3} \text { HeadEmployed } \\
& +\alpha_{4} \text { SpouseEmployed } d_{i, t}+\alpha_{5} \text { nadults } s_{i, t}+\alpha_{6} \text { nchildren } 0 \_2_{i, t} \\
& +\alpha_{7} \text { nchildren } 34_{i, t}+\alpha_{8} \text { nchildren } 5 \_11_{i, t}+\alpha_{9} \text { nchildren } 12_{-}{ }_{1} 5_{i, t} \\
& +\alpha_{10} \text { nchildren } 16 \_18_{i, t}+\text { year }_{t}+z_{i, t},
\end{aligned}
$$

where Age is the age of the head of household; HeadEmployed and SpouseEmployed are dummies taking a value of 1 if the head is in employment or if there is an employed spouse in the household; nadults is the number of adult household members; nchildren $0 \_2$ refers to the number of children aged 0-2, and similarly for the remaining variables. This formulation allows changes in family composition and changes in the age of the head of household to influence consumption growth. The employment status dummies address the finding that the empirical fit of Euler equations improves 
much if one conditions on changes in employment status. ${ }^{19}$ The year dummies capture both the common impact of macro shocks and, since we assume common interest rates, $r_{i, t}=r_{t}$, the influence of the term $\frac{1}{\rho} \ln \left(1+r_{i, t}\right){ }^{20}$ In addition, $z_{i, t}$ captures the influence of unobserved preference shifters. Note that this specification takes account of unobserved heterogeneity in consumption levels through the household-specific constant $\alpha_{0 i}$ which is differenced out. Also, since we take consumption growth to refer to a yearly change for all observations, the change in the age of the head of household will be one year across observations. Consequently, the coefficient $\alpha_{1}$ will be buried in the intercept.

Measurement error. Both own consumption growth and the growth of average rich consumption are noisily measured. In the consumption literature, measurement error in food consumption data has mostly been assumed to be multiplicative in levels and additive in logs (Dynan, 2000; Alan et al., 2009). In our case, taking midpoints introduces additional measurement error. Because the bandwidth is increasing in the amount spent, the measurement error should still take a form that is approximately multiplicative in levels (and additive in logs). We therefore work under the assumption of classical measurement error in our consumption variables. As a robustness check, we reestimate our main specifications using interval regression.

Taking averages over all rich households in each county and year should remove the individual measurement error in rich consumption. However, mean rich consumption is an estimate for the population mean in a given county. The sampling variation associated with estimating average rich consumption out of a small number of observations adds an additional layer of measurement error. Assuming that this measurement error also takes an approximately multiplicative form, we have:

\footnotetext{
19 Potential reasons for this include non-separabilities in the utility function, costs associated with taking up a job or the substitution of home production with market goods (Attanasio and Browning, 1995).

${ }^{20}$ Alternatively, one could use household-specific interest rates constructed through differences in marginal tax rates. However, the tax unit in the UK is not the household but the individual. Moreover, marginal tax rates do not vary continuously across individuals. For these reasons we work under the assumption of common interest rates.
} 


$$
\begin{aligned}
& \hat{c}_{i, t}=c_{i, t}+u_{i, t}, \\
& \overline{\hat{c}}_{i, t}^{R}=\bar{c}_{i, t}^{R}+v_{i, t},
\end{aligned}
$$

where $\hat{c}_{i, t}$ and $\overline{\hat{c}}_{i, t}^{R}$ are observed own log consumption (of a non-rich household) and observed average log consumption among rich households in the household's reference group, respectively. Consequently, the error term in the estimating equation will take the form:

$$
e_{i, t}=\epsilon_{i, t}+\Delta u_{i, t}-\gamma \Delta v_{i, t}+w_{i, t}+\frac{1}{\rho} \Delta z_{i, t}
$$

where $\epsilon_{i, t}$ again denotes the forecast error, $w_{i, t}$ denotes the non-log-linear part of consumption growth, and $\Delta z_{i, t}$ captures the change in the influence of unobserved preference shifters. Under the assumptions of classical measurement error, mismeasurements induce a serial correlation with an MA(1)-structure in the error term. Measurement error in the dependent variable will reduce the precision of our estimates but will not give rise to inconsistency. However, measurement error in the independent variable, the growth of average consumption among rich households, will lead to a negative correlation between observed values and the error term. This will drive the OLS estimate of $\gamma$ to zero.

The reflection problem. Our empirical specification is subject to the reflection problem (Manski, 1993). Accordingly, there are three possible sources of correlation between own outcomes and reference group outcomes: First, there might be direct effects of peers' outcomes on own outcomes (endogenous effects). In our context, this refers to the genuine influence of the growth in average rich consumption on own consumption growth: relative concerns for consumption at the top. Second, there could be direct effects of exogenous characteristics of reference groups on own outcomes, while these characteristics also influence reference group outcomes (exogenous effects). This situation would apply if, say, age and family composition of rich households influence their own consumption, while at the same time exerting a direct influence on the consumption of non-rich households. In this case, exogenous 
reference group characteristics would be part of the unobserved preference shifters $z_{i, t}$. Third, households that are members of the same reference group are facing the same institutional environment, they may be subject to the same shocks and they might share similar individual characteristics (correlated effects). In our case, correlated effects may arise because households in the same county are exposed to the same county-specific business cycles, the same local prices or the same advertisement. These effects are likely to lead to a positive correlation of the independent variable with the error term. Also, positive sorting of households with similar unobserved characteristics such as similar degrees of patience into the same county might give rise to correlated effects.

Regarding the possibility of exogenous effects, we check the robustness of our findings to including changes in averages of demographic characteristics of rich households into our specifications. Moreover, by including county dummies we account for the impact of correlated effects on consumption growth as long as they are time-invariant. This formulation is equivalent to specifying a reference-group specific discount factor and should also control for part of the influence of countyspecific price trends. In addition, we include the county-level employment rate as a control for county-specific business cycles. ${ }^{21}$

Estimating equation. Taking these considerations into account, our estimating equation for the Euler equation is given by:

\footnotetext{
${ }^{21}$ In line with changes in the data collection procedures of the Office for National Statistics (ONS), we use data on county-level employment rates for all individuals aged 16-64 from the Labour Force Survey (LFS) for the years 1997-1998, data from the Local Area Labour Force Survey (LALFS) for the years 1999-2003, and data from the Annual Population Survey (APS) for the period 2004-2008. According to the ONS, these figures should be comparable. For 1997-2003 we take the average employment rate over the period starting in March of a given year and ending in February of the following year. The BHPS interviews are conducted between September and November of a given year, that is, roughly in the middle of this period. The reference period shifts in 2004 with the introduction of the APS one month to the period from April of a given year until March of the following year.
} 


$$
\begin{aligned}
\Delta \hat{c}_{i, t} & =\kappa+\gamma \Delta \overline{\hat{c}}_{i, t}^{R}+\frac{1}{\rho} \alpha_{2} \Delta \text { Age }_{i, t}^{2}+\frac{1}{\rho} \alpha_{3} \Delta \text { HeadEmployed } d_{i, t}+\frac{1}{\rho} \alpha_{4} \Delta \text { SpouseEmployed }_{i, t} \\
& +\frac{1}{\rho} \alpha_{5} \Delta \text { nadults }_{i, t}+\frac{1}{\rho} \alpha_{6} \Delta \text { nchildren } 0 \_2_{i, t}+\frac{1}{\rho} \alpha_{7} \Delta \text { nchildren } 3 \_4_{i, t} \\
& +\frac{1}{\rho} \alpha_{8} \Delta \text { nchildren } 5 \_11_{i, t}+\frac{1}{\rho} \alpha_{9} \Delta \text { nchildren } 12 \_15_{i, t}+\frac{1}{\rho} \alpha_{10} \Delta \text { nchildren } 16 \_18_{i, t} \\
& +\alpha_{11} \text { EmploymentRate }_{i, t}+\frac{1}{\rho} \text { year }_{t}+\text { count }_{i}+e_{i, t} .
\end{aligned}
$$

The estimation of this equation by OLS is likely to produce a biased estimate of $\gamma$, but the direction of the bias is ambiguous. On the one hand, classical measurement error can be expected to induce attenuation bias and drive the estimate of $\gamma$ to zero. On the other hand, controlling for the local employment rate may not be sufficient to fully control for common shocks and other correlated effects. Any remaining spurious correlation between own consumption and rich consumption will show up as an upward bias of the parameter estimate. Moreover, the changes in employment status of head and spouse are jointly determined with consumption growth and will therefore introduce additional bias.

In order to obtain consistent estimates in the presence of these problems, we estimate the Euler equation by 2-step GMM (Hansen, 1982). ${ }^{22}$ We treat the growth in average log consumption of rich households as well as the changes in employment status as endogenous. Valid instruments must be uncorrelated with the forecast error, i.e. they must be part of the information set at time $t-1$. Moreover, they must be uncorrelated with the measurement errors in the independent and the dependent variable, the non-log-linear component of consumption growth and changes in unobserved preference shifters. We treat changes in family composition such as the arrival of children as completely foreseen at time $t-1$, so we include them directly into our set of instruments. The excluded instruments used in our baseline estimations are the lag of the average log income of rich households, the lagged growth rate of the 80th percentile of the local earnings distribution as well as

\footnotetext{
${ }^{22}$ The assumption of rational expectations together with the assumption on the structure of the error term imply a set of population orthogonality conditions. Specifically, the expectation of the products of the error term and valid instruments (as explained in the main text) should be equal to zero. GMM estimates are the parameter values that minimise the weighted distance of the sample analogues of these moments from zero.
} 
the lagged employment status of head and spouse. Our main independent variable varies at the county level and ignoring potential correlations of the error term within counties will give rise to biased standard errors (Angrist and Pischke, 2009, p.319). Therefore, throughout the analysis we report standard errors and test statistics that are robust to heteroskedasticity and clustering at the county level. This also takes account of the serial correlation in the error term that is induced by measurement error. Likewise, the GMM weighting matrix is adjusted to allow for clustering and arbitrary heteroskedasticity. ${ }^{23}$

Sample selection. Before estimating equation (7), we have to further restrict our study sample. We start with the sample of 18,910 non-rich observations aged 20-64, having deleted small cells. The exclusion restriction in our GMM estimations is that conditional on the included exogenous variables, consumption growth is orthogonal to everything that is part of the information set at time $t-1$. This restriction is not valid for households facing liquidity constraints. Consequently, estimating an Euler equation for such households results in biased parameter estimates (Alan et al., 2009). While we cannot identify liquidity-constrained households, we exclude the households from the low-income sample of the BHPS because they are "likely" to be liquidity-constrained (982 observations). As we are interested in consumption growth, we also have to exclude all observations that are not part of a two-year spell, deleting another 3,341 observations. Finally, we have to drop first differences for which the lagged growth in the 80th percentile of the local earnings distribution, which we use as an instrument, is missing. This deletes further 1,097 observations from the years 1997 and 1998. The final sample for the estimation of the Euler equation consists of 13,490 non-rich observations and 10,037 first differences living in 2,914 households and 50 counties. Table 1 provides summary statistics of the final sample. For example, we can see that the average household head is approximately 44 years old, that $31 \%$ of the household heads are women, that approximately $90 \%$ of the

\footnotetext{
${ }^{23}$ Our independent variable is an estimate for the growth of rich consumption in the population. Given that the sampling variation of this estimate affects the asymptotic distribution of our main estimates, conventional standard errors will be biased (Pagan, 1984). While bootstrapping standard errors is a common procedure to deal with the potential bias of the standard errors, such a procedure is non-trivial in our case. The key difficulty is that for each bootstrap draw we would have to re-sample rich observations at the county level, sometimes out of a very small number (10 at the minimum). In general, we would expect standard errors to increase if the additional sampling variation is taken into account.
} 
households are based in England and that the average number of rich observations per cell is around 22 .

\subsection{Main results}

OLS results. Can the growth of consumption among rich households explain the consumption growth of non-rich households? Table 2 presents the results of the estimation of the Euler equation (7). All columns include demographic controls (changes in family composition and age squared) as well as year and county dummies. OLS estimates are presented in columns 1 to 3 . Column 1 shows that conditional on the included controls, there is no significant correlation between own consumption growth of non-rich households and the growth of the average consumption of rich households in a household's county of residence. The estimate of $\gamma$, i.e. the estimated coefficient on $\Delta \overline{\hat{c}}_{i, t}^{R}$, is 0.015 with a standard error of 0.028 . Columns 2 and 3 add the county-level employment rate (i.e., a business cycle indicator) and changes in the labour market status of head and spouse as controls. The coefficient estimates for the parameter $\gamma$ remain at small positive values and not statistically significant. One reason for this finding could be that classical measurement error in the independent variable leads to attenuation bias and thus drives the estimated coefficients to zero. Upward-bias due to spurious correlation through county-specific shocks, on the other hand, does not seem to be severe.

GMM results. Columns 4 to 6 present reestimations of columns 1 to 3 using GMM and the baseline set of instruments as described in the previous section. Columns 4 and 5 show a small increase in the estimated parameter as compared to the OLS estimates in columns 1 and 2, consistent with the idea of attenuation bias of the OLS estimates due to measurement error. Column 6 displays our preferred specification which controls for changes in the employment status of head and spouse. The estimated coefficient is reduced to a size of 0.012 with a standard error of 0.090. To illustrate the small economic magnitude, the estimates imply that a 1 percentage point increase in the growth of average rich consumption will increase non-rich consumption growth by approximately 0.012 percentage points. ${ }^{24}$ Across

\footnotetext{
${ }^{24}$ This is true only approximately since our independent variable is defined as the growth in the average log consumption instead of the growth in log average consumption of rich households.
} 
specifications, the point estimates of $\gamma$ remain at small positive values and not significantly different from zero.

Other findings. Consistent with previous findings in the literature, changes of the labour market status of head and spouse have a significantly positive effect on consumption growth. For instance, if the head of household switches from "out of employment" into employment, household consumption grows by around 11 percent. The estimated coefficient on age squared is significantly negative throughout, consistent with the familiar hump shape of consumption over the life-cycle (Attanasio and Browning, 1995). Moreover, as shown in Table A2 in the appendix, changes in the number of adults and children (below age 16) affect consumption growth in a positive way, as expected. The $R^{2}$ of all estimations is around 0.10 , indicating that a non-negligible fraction of the variance of observed consumption growth in our sample can be explained by the included controls. Unfortunately, we cannot compare this figure to other studies estimating log-linearised Euler equations, such as Dynan (2000) or Alvarez-Cuadrado et al. (2012), since these studies do not report the $R^{2}$.

Threats to identification. We test the validity of our instruments using the Hansen $J$-statistic which is proportional to the minimised value of the GMM criterion function. Under the null hypothesis that all instruments are uncorrelated with the error term, the statistic has a $\chi^{2}$-distribution with degrees of freedom equal to the number of overidentifying restrictions. In our case, the number of excluded instruments exceeds the number of endogenous explanatory variables by one, so under the null the test statistic is distributed according to a $\chi^{2}(1)$. The $p$-values of the $J$-test are all between 0.86 and 0.95 , so we cannot reject the null that our instruments are valid.

In the presence of weak instruments, instrumental variable estimators are subject to severe finite sample bias into the direction of the corresponding OLS estimates (Bound et al., 1995). Thus, we check whether our instruments are only weakly correlated with the endogenous explanatory variables. With more than one endogenous regressor, high values of conventional $F$-statistics on the excluded instruments in the first stages are not sufficient to rule out problems of weak identification. We therefore report first stage $F$-statistics constructed as proposed in Angrist and Pischke (2009): A given endogenous explanatory variable is regressed on the first-stage predictions 
of all other endogenous regressors and on all exogenous variables. The residuals of this regression are regressed on the excluded instruments. The Angrist-Pischke $F$-statistic is then computed as the $F$-statistic on the hypothesis that the coefficients on the excluded instruments are jointly zero in this regression. Critical values of this statistic are unavailable, but as a rule of thumb, values greater than 10 indicate that weak instruments should not be a major concern (Angrist and Pischke, 2009, p.213). ${ }^{25}$ We report the values of these $F$-statistics at the bottom of Table 2 . The value for the growth of average rich consumption is around 29 for the specifications 4 to 6 , indicating that the lag of the average log income of rich households and the lagged growth of the 80th percentile are informative instruments for this variable. Likewise, the values for the changes in employment status are outside the problematic range. Table A3 in the appendix reports the first stage regressions for the results in columns 4 to 8 . A higher level of lagged average log income of rich households predicts lower growth of average consumption in the rich group. Similarly, a higher lagged growth in the 80th percentile of the labour earnings distribution implies lower current growth of average rich consumption. ${ }^{26}$

Just-identified specifications. Column 7 reports the results of a GMM estimation using only lagged average income of the rich as instrument for the growth in rich consumption. Since this variable was estimated out of the BHPS sample, one might be worried that the measurement error in this variable is correlated with the measurement error in the main independent variable. Column 8 therefore shows estimates using only the lagged growth of the 80th percentile as instrument for the growth of average rich consumption. Because this variable is taken from the much larger ASHE, it is unlikely to be correlated with the sampling variation of the BHPS. In both cases, the estimate of $\gamma$ remains at a small positive value and not statistically different from zero.

Discussion. Overall, we find no evidence of an effect of the change in the

\footnotetext{
${ }^{25}$ Sanderson and Windmeijer (2013) criticise that this procedure does not take into account that a linear projection of the other endogenous variables is partialled out instead of the variables themselves.

${ }^{26}$ We checked the robustness of our findings to using a Limited Information Maximum Likelihood (LIML) estimator which is known to be less subject to finite sample bias than GMM in the presence of weak instruments (Flores-Lagunes, 2007). Throughout, the estimates of $\gamma$ remained virtually unchanged.
} 
average consumption among rich households on the consumption growth of nonrich households. Our findings therefore differ qualitatively from the two existing studies on relative concerns for the consumption of neighbouring households in the intertemporal allocation of expenditure. Ravina (2007) and Alvarez-Cuadrado et al. (2012) report estimates of $\gamma$ between 0.20 and 0.30 that are significantly different from zero. Our paper differs from these studies in that the reference point is provided by rich households who are not part of the study sample of non-rich households. In Ravina (2007) the measure of reference group consumption are city-level sales, while in Alvarez-Cuadrado et al. (2012) it is the average consumption among all other households living in the same census tract. In unreported estimations we changed the reference point for a given non-rich household from average rich consumption to the average consumption among all other non-rich observations, leaving the rest of our estimation strategy unchanged. The coefficient estimates in the GMM specifications increased to sizes between 0.23 and 0.27 with $p$-values between 0.03 and 0.06 . This is basically the same range of values found in previous studies (Ravina, 2007; AlvarezCuadrado et al., 2012), which is both a very remarkable and reassuring finding for our main estimates.

There is a methodological advantage of our focus on "trickle-down" externalities of the consumption of rich households: As recently argued by Angrist (2014), a clear separation of individuals who provide the reference point from the individuals that are part of the study sample might help to overcome mechanical correlations between own and reference group outcomes in social interaction models. Our strategy implicitly assumes that rich households choose their consumption independently of non-rich households' consumption. This assumption can be justified by the evidence in the happiness literature suggesting that comparisons are upward rather than downward (Ferrer-i Carbonell, 2005; Senik, 2009; Card et al., 2012). 


\section{Robustness checks}

\subsection{Alternative definitions of reference groups}

A potential reason for the zero finding is that a purely geographic definition of reference groups is inadequate to capture the relative concerns that are actually important in the choices of non-rich households. Other studies of interdependent preferences often assume that households compare themselves primarily with households that share certain demographic characteristics (Alessie and Kapteyn, 1991; Maurer and Meier, 2008; Lewbel et al., 2013). To explore this idea, we synthesize the geographic definition of reference groups used so far with definitions along two demographic dimensions, namely educational attainment and age cohort. Both dimensions have the advantage that they are (almost) constant over our sample period. ${ }^{27}$

First, we classify households into five groups according to the highest education level achieved by the head over the sample period (less than GCSE/O-level, GCSE/Olevel, A-level, HND, university degree). Within each educational group, government office region and year, we compute the average consumption of those whose current labour earnings exceed the 80th percentile of the region-level earnings distribution. We subsequently drop these "rich" observations from our sample and repeat our main estimations. $^{28}$ Columns 1-3 in Table 3 present the results of this exercise. OLS results are shown in column 1. Column 2 shows GMM results instrumenting the change in rich consumption with lagged average rich income, while column 3 adds the lagged change in the fraction of spouses employed in the rich group as an instrument. ${ }^{29}$ Across specifications, the coefficient estimates are of small economic size and not statistically significant. Second, we repeat the exercise but instead of educational attainment we classify households into 8-year cohorts according to the age of the head of household in 1997. The results of this exercise are presented in columns 4-6. Although the coefficient estimates remain insignificant, GMM results are larger in

\footnotetext{
${ }^{27}$ Only around 2 percent of the observations in our sample are out of households for which the educational attainment of the head changes over the sample period.

${ }^{28} \mathrm{We}$ conducted the sample selection in the same way as before. Among others, we again deleted cells with less than 10 rich observations.

${ }^{29} \mathrm{We}$ could no longer use the lagged growth in 80th percentile of the region-level earnings distribution as an instrument here because this variable does not vary across educational groups or age cohorts within a given region.
} 
size than previously. However, the first-stage $F$-statistics indicate problems of weak identification, suggesting that these estimates should be taken with caution. Overall, we conclude that our main results are robust to alternative definitions of reference groups.

\subsection{Exogenous effects}

It is possible that exogenous effects in the sense of Manski (1993) lead to biased estimates of the parameter $\gamma$ due to omitted variables. That is, exogenous characteristics of rich households that influence their consumption behaviour could exert a direct influence on the consumption behaviour of non-rich households. To account for this possibility, we add changes in the average numbers of adults and children, the change in the average age of the head of household as well as the growth of average log income among rich households as controls in our specifications. We encountered problems of weak instruments in this exercise. To deal with these problems, we only check robustness of the specification without employment status dummies, reducing the number of variables that need to be instrumented. In addition, we reduce the degree of overidentification and estimate just-identified specifications, which are likely to be more robust in the presence of weak instruments (Angrist and Pischke, 2009, p.209). We instrument the change in rich consumption with the lagged growth of the 80th percentile of the earnings distribution. As an instrument for the change in rich income we use lagged average log total family hours worked among rich households. We treat changes in average age and family composition among rich households as exogenous. The results of this exercise are shown in Table 4. Throughout, the estimate of $\gamma$ remains at a small positive value and not statistically significant, suggesting that exogenous effects are not an important confounding factor in our analysis.

\subsection{Liquidity constraints}

Our model assumes that households are not liquidity constrained. However, in real life some households are likely to be constrained. While in our previous analysis we excluded households from the low income sample and households with a very young 
head (less than 20) to account for liquidity constraints, it may well be the case that this selection is not stringent enough. Therefore, we repeat our main estimations applying another method of identifying liquidity-constrained households.

Estimating Euler equations using data from the PSID, Alan et al. (2009) exclude household observations that do not bring forward any liquid assets to the current period. Since the BHPS does not provide information on asset holdings, we instead exclude observations who report zero current investment income. This reduces our sample size from 10,037 to 4,105 observations, while the number of counties remains 50 . Table 5 reports the results of these estimations. Notably, the change in employment status of the head of household is no longer a significant determinant of consumption growth, while the change in the employment status of spouse still enters significantly at the 1 percent level. However, even though the coefficient estimates on the growth of rich consumption increase to values between 0.05 and 0.07 , they remain statistically insignificant. This suggests that liquidity constraints are not responsible for our previous findings.

\section{$5.4 \quad$ Interval censoring}

Taking midpoints of the expenditure bins may induce non-classical measurement error in both the dependent and the independent variables. Both cases would give rise to a bias of our parameter estimates whose direction is unknown (Angrist and Krueger, 1999, p.1341). If measurement error in the consumption of individual rich households is non-classical, it may no longer be removed through averaging over all rich observations in a county and year. However, we expect the problem to be more severe for our dependent variable, i.e. own consumption growth, where we do not average over several observations. To address this concern, we reestimate

the OLS specifications of the Euler equation using interval regression (Stewart, 1983), a generalisation of the Tobit model that allows the dependent variable to be measured in potentially overlapping bands of arbitrary size. We calculate the minimum and maximum possible consumption growth for each observation according to the expenditure bins, setting the values to missing if expenditure in any of the two periods is in the highest category. This slightly reduces the number of observations 
available for this robustness check. Table 6 shows the results of this exercise. Columns 1-3 show OLS estimates while columns 4-6 report the corresponding results of interval regressions. As can be seen, the coefficient estimates on $\Delta \overline{\hat{c}}_{i, t}^{R}$ increase in the latter specifications, even though they remain of small economic size and not statistically significant. The coefficient estimates on the other independent variables in the interval regressions are very similar to their OLS counterparts. While this exercise indicates that taking midpoints biases our estimate of $\gamma$ toward zero, the bias does not seem big enough to account for our main finding, i.e. the lack of upward-looking relative concerns among non-rich households. This is reassuring, and consistent with the results in Etheridge (2012), who demonstrates that taking midpoints of banded consumption data should not give rise to economically meaningful biases.

\subsection{Heterogeneous relative concerns}

This subsection investigates the possibility that some households -depending on their own characteristics or those of their location- might be more prone than others to respond to the consumption of rich households in their reference group. We checked for the presence of such heterogeneous effects using both OLS and GMM. However, including interaction terms increased the number of endogenous explanatory variables, leading to weak instrument problems in many of the GMM estimations. We therefore only report OLS results, and explore heterogeneity across six dimensions, namely: inequality in the county, population density in the county, age of the household head, marital status of the household head, educational attainment of the household head, and income of the household head.

Inequality. Column 1 of Table 7 exploits the idea that the effect might differ according to the degree of inequality in an area. A higher degree of inequality means that rich households are "further away" from non-rich households and the society in a county is more segregated. Non-rich households in high inequality areas may therefore be less likely to compare themselves to their rich co-residents. Additionally, one could argue that consumption as a signal for status will be more effective if the difference in income between the two groups is less clear-cut. Accordingly, we would expect the effect to be greater if inequality is lower. Since inequality is potentially 
endogenous, we measure inequality in a given county by the $90-50$ ratio of the earnings distribution in 1997, the baseline year of our sample. ${ }^{30}$ Subsequently, we divide our sample at the median into a high inequality and a low inequality group, and define the dummy variable LowIneq, which takes a value of 1 if the observation is from a county which was classified as a low inequality area according to a median split of our sample along the 90/50-ratio of the county-level earnings distribution in 1997, and 0 otherwise. ${ }^{31}$ The estimated coefficient on the interaction of the growth of average rich consumption with the low inequality dummy is positive and significantly different from zero at the 10 percent level. Accordingly, in low inequality areas an increase in the growth of rich consumption by 1 percentage point leads to an increase in own consumption growth by about 0.09 percentage points.

Population density. One mechanism behind the potential effect of rich consumption on non-rich consumption is the search for status by non-rich households (Frank, 1985). In his "Theory of the Leisure Class", Veblen (1899) stressed that such costly ways of status signalling will have a more prominent role if social interactions are more anonymous, as it is the case in cities. Moreover, recent evidence in the happiness literature suggests that city dwellers compare their incomes to the incomes of their peers more intensely than residents of more rural areas (Clark and Senik, 2010, p.584). These points imply that the effect should be increasing in the population density of an area. On the other hand, one could argue that the visibility of consumption is greater if population density is lower, leading to the opposite effect. We again measure population density by its baseline value in 1997 and divide the sample into a high and a low density group, defining the dummy variable LowDens, which takes a value of 1 if the observation is from a county which was classified as a low density area according to a median split of our sample along residents per square kilometer in 1997, and 0 otherwise. ${ }^{32}$ The estimates shown in column 2 indicate that, consistent with the ideas in Veblen (1899), relative concerns (for consumption at the top) are more important in areas with higher population density.

\footnotetext{
${ }^{30}$ A different strategy would be to instrument the current level of inequality with its value in 1997. Since following this strategy led to weak instrument problems, we decided to instead use the baseline value directly.

${ }^{31}$ The 90th percentile of the earnings distribution was not available for all counties in our sample, leading to a slight reduction in sample size. The data source is the ASHE.

${ }^{32}$ The data source is the mid-year population estimates from the ONS.
} 
Age. Relative concerns could vary by age group. On the one hand, younger individuals switch their job and their social environment more often. Therefore, they engage more often in anonymous social interactions. Also, younger individuals may feel a stronger need to signal status through consumption to set themselves apart from their peers whose average incomes are still comparatively low. These points imply that younger individuals could be more prone to emulate the spending habits of the rich. On the other hand, increasing age may capture the effect of the relaxing of liquidity constraints (Attanasio et al., 1999). Households facing liquidity constraints may not react to changes in the growth in rich consumption, so the effect could be increasing in age. We construct the dummy variable Old that takes the value 1 if the head of household is aged above 42 and 0 otherwise. This value is in the middle of the age range in our sample (20-64) and again roughly divides the sample by half. The results shown in column 3 give no indication for different effects across age groups.

Marital status. Competition for marriage partners might induce individuals to act as if they had relative concerns in consumption (Hopkins, 2008). In the present case, married individuals may feel less need to signal status through imitating the consumption of rich households. Column 4 examines whether the effect differs between households whose head is married and households whose head is unmarried. We define the dummy variable Married $_{-1}$, which takes a value of 1 if the head of the household was married in the previous year. ${ }^{33}$ We find no empirical support for this hypothesis: The point estimate on $\Delta \overline{\hat{c}}^{R} \times$ Married $_{-1}$ is positive, albeit not statistically significant.

Education. While emulating the consumption of the rich may be one way of achieving status, another way could be the accumulation of human capital. ${ }^{34}$ Thus, individuals with higher educational attainment may feel less need to signal status through consumption. In column 5, the dummy variable LowEduc $c_{-1}$ takes the value 1 if the lagged educational attainment of the head is below A-level and 0 otherwise. As expected, the coefficient on the growth of rich consumption decreases in size and

\footnotetext{
${ }^{33}$ The married dummy is lagged because if the hypothesized mechanism was true, marital status would be endogenous.

${ }^{34}$ See the recent work by Moav and Neeman (2012) based on a trade-off between conspicuous consumption and human capital as signals for unobserved income.
} 
the coefficient on the interaction term is positive and marginally significant. This points to the presence of relative concerns (albeit weak) for households whose head has lower educational attainment.

Income. Frank et al. (2010) argue that households compare their consumption to the consumption of those who are located only slightly higher in the income distribution. Thus, while the consumption of the rich may be a reference point for the middle class, lower income households may instead compare their consumption to the consumption of middle-income households. We explore this possibility in column 6. The dummy MiddleInc-1 takes a value of 1 if the lagged earnings of the main earner exceeded the median of the county-level earnings distribution and 0 otherwise. Consistent with the ideas in Frank et al. (2010), the coefficient estimate on the interaction term of this dummy with the growth in rich consumption is positive, while the estimate on the growth in rich consumption is now even closer to zero. However, neither of the estimates are significantly different from zero.

Adjusting for multiple testing. If we estimate equations (1)-(6) simultaneously and test the null hypothesis that the coefficients on $\Delta \overline{\hat{c}}^{R} \times$ LowIneq, $\Delta \overline{\hat{c}}^{R} \times$ LowDens, $\Delta \overline{\hat{c}}^{R} \times$ Old,$\Delta \overline{\hat{c}}^{R} \times$ Married $_{-1}, \Delta \overline{\hat{c}}^{R} \times$ LowEduc $_{-1}$, and $\Delta \overline{\hat{c}}^{R} \times$ Middle Inc $_{-1}$ are all zero, the Wald test generates a $\chi^{2}$ value (with 6 degrees of freedom) of 13.19, with an associated $p$-value of 0.0400 . Hence, we reject the null hypothesis at the $5 \%$ level. All in all, we find some (correlational) evidence of heterogeneous effects across county and household characteristics. In particular, there are relative concerns (for consumption at the top) in counties with relatively low income inequality or relatively high population density. Households whose head has relatively low educational attainment are also subject to relative concerns for consumption at the top, which is consistent with a trade-off between conspicuous consumption and human capital as signals for unobserved income (Moav and Neeman, 2012).

\subsection{Attrition}

Attrition can lead to biases in panel data estimations if it is not random, even if the variables that predict attrition are conditioned on (Wooldridge, 2010, p.828). Testing for non-random attrition is straightforward if all units are observed in the base period 
and attrition is an absorbing state. However, our sample selection procedure, in particular the deletion of small cells, leads to a different structure of our dataset: Not all households are observed in the base period and households are allowed to re-enter after they have left the sample.

We tested for non-random attrition in the following way: For each time period we constructed a dummy variable equal to 1 if the household leaves the sample in the next period. Subsequently, we simultaneously estimated a set of regressions with observable household characteristics in the given period as the vector of dependent variables and the attrition dummy as the independent variable. We then tested the hypothesis that the coefficients on the dummy variable are jointly zero in these regressions. This procedure yielded evidence for non-random attrition. In particular, leavers had a significantly lower income than stayers. This form of attrition has been observed in previous studies of the BHPS. However, according to these studies, the effect is of limited economic magnitude (Jenkins, 2010). We repeated the procedure with a dummy variable equal to 1 if the household has joined the sample in a given period. Joiners are significantly younger and less often married than households that have already been in the sample in the previous period. This is to be expected because they are often off-springs of initial sample members. One concern is that these households may be liquidity-constrained, rendering the Euler equation approach inadequate. However, the robustness check above that applies a narrower definition of liquidity constraints indicates that this is not a major concern.

Reassuringly, there were only very few cases in which own consumption growth or the growth of rich consumption were significant predictors of joining or leaving the sample. Thus, while the possibility of non-random joining or leaving should lead one to interpret our results cautiously, we do not expect it to have a major influence. Given the small magnitude of our coefficients estimates, it is unlikely that the qualitative direction of our results would be affected. ${ }^{35}$

\footnotetext{
${ }^{35}$ In addition, we reestimated our main specifications using only those households who are observed in every time period that their county of residence appears in our sample. Our results remained very similar.
} 


\subsection{Additional checks}

We conducted a range of additional robustness checks that we do not report but are available upon request. Amongst others, we changed the definition of the dependent variable from the growth rate of the average consumption to the average growth rate of consumption among rich households. This formulation is equivalent to the one used in Maurer and Meier (2008). Moreover, we checked robustness to using different thresholds in our classification of "rich" and "non-rich" such as the 70th and the 75th percentile. Similarly, we repeated the exercise at the higher, regional level. The number of rich observations in each cell increased in these cases, making the estimates of mean consumption and income among rich households less noisy. Throughout, the results of these additional robustness checks were very similar to our primary findings. That is, the estimates of $\gamma$ remained statistically insignificant and small in absolute size.

Finally, we also examined potential effects on the intratemporal allocation of expenditure, exploiting the insight that relative concerns might primarily apply to socalled status and positional goods with a high degree of visibility (Frank, 1985; Heffetz, 2011; Quintana-Domeque and Turino, 2013). Decomposing total food consumption into a more visible (food consumed at restaurants) and a less visible component (food consumed at home), we conducted a test for conspicuous consumption proposed in De Giorgi et al. (2012). Accordingly, an increase in rich consumption of visible goods should induce non-rich households to shift expenditure away from non-visible and towards visible goods. We find no evidence for this hypothesis. While coefficient estimates go into the expected direction, they are not significantly different from zero.

\section{Conclusion}

This paper contributes to the literature on relative concerns for the consumption of rich households among non-rich households. Whereas previous studies examine effects of such relative concerns on savings rates in a static setting (Frank et al., 2010; Bertrand and Morse, 2013), we test their implications in the context of a dynamic 
model assuming forward-looking households. We estimate the Euler equation implied by this model on household food consumption data from the UK.

According to both our OLS and GMM estimates, for the population of non-rich individuals as a whole, there is no evidence of relative concerns for consumption at the top. These results are robust to alternative definitions of the reference group, the presence of exogenous effects and liquidity constraints, and the use of interval regressions. Our findings differ qualitatively from those in Bertrand and Morse (2013), who document that higher incomes and consumption among rich households have induced non-rich households in the US to consume a larger fraction of their incomes. According to our main estimates, upward-looking comparisons do not generally exert a strong influence on consumption outcomes.

However, we find some (correlational) evidence of heterogeneous effects across county and household characteristics, which is robust to simultaneous estimation. In particular, there are relative concerns (for consumption at the top) in counties with relatively low income inequality -consistent with the idea that non-rich households in low inequality areas are more likely to compare themselves to their rich co-residentsor relatively high population density -consistent with the idea that consumption as signal for status will have a more prominent role if social interactions are more anonymous. Households whose head has relatively low educational attainment are also subject to relative concerns for consumption at the top, which is consistent with a trade-off between conspicuous consumption and human capital as signals for unobserved income (Moav and Neeman, 2012).

The suggestive evidence for relative concerns in low inequality areas indicates that increasing top income shares could have an ambiguous effect: When income growth concentrates at the top, middle-class households will be exposed to higher consumption among their rich co-residents. At the same time, however, the society might become more segregated. Consequently, the consumption of rich co-residents may become less relevant as a reference point in the consumption choices of poorer households. As a result, increasing income inequality may not necessarily induce non-rich households to adjust their consumption choices to keep up with their rich co-residents.

We have discussed several caveats that should be kept in mind in the interpretation 
of our main findings. Among others, it is important to remember that the model tested in this paper implies that higher growth of the consumption of rich households induces non-rich households to adopt a path with lower initial consumption but with a higher consumption growth rate. This restriction could be too strong to adequately capture the consumption behaviour of these households. 


\section{References}

Abel, A. B. (1990): "Asset Prices under Habit Formation and Catching up with the Joneses," American Economic Review, 80(2), 38-42.

Airaudo, M., And L. Bossi (2014): “Trickle-Down Consumption, Monetary Policy, and Inequality," Working Paper.

Alan, S., O. Attanasio, and M. Browning (2009): "Estimating Euler Equations with Noisy Data: Two Exact GMM Estimators," Journal of Applied Econometrics, 24, 309-324.

Alesina, A., R. Di Tellab, and R. MacCulloch (2004): "Inequality and Happiness: Are Europeans and Americans Different?," Journal of Public Economics, 88, 2009-2042.

Alessie, R., And A. Kapteyn (1991): "Habit Formation, Interdependent Preferences and Demographic Effects in the Almost Ideal Demand System," Economic Journal, 101(406), 404-419.

Alvarez-Cuadrado, F., J.-M. Casado, J. Labeaga, and D. Sutthiphisal (2012): "Envy and Habits: Panel Data Estimates of Interdependent Preferences," Banco de Espana Working Paper, 1213.

Angrist, J. D. (2014): "The Perils of Peer Effects," Labour Economics, forthcoming. Angrist, J. D., And A. B. Krueger (1999): "Empirical Strategies in Labor Economics," in Handbook of Labor Economics, ed. by O. C. Ashenfelter, and D. Card, vol. 3a, chap. 23, pp. 1277-1366. Elsevier Science B.V.

Angrist, J. D., And J.-S. Pischke (2009): Mostly Harmless Econometrics: An Empiricist's Companion. Princeton University Press.

Arrow, K. J., and P. S. Dasgupta (2009): "Conspicuous Consumption, Inconspicuous Leisure," Economic Journal, 119, 497-516.

Atkinson, A. B., T. Piketty, and E. Saez (2011): "Top Incomes in the Long Run of History," Journal of Economic Literature, 49(1), 3-71. 
Attanasio, O. (1999): "Consumption," in Handbook of Macroeconomics, ed. by J. Taylor, and M. Woodford, vol. 1, chap. 11, pp. 741-812. Elsevier Science B.V. Attanasio, O., J. Banks, C. Meghir, and G. Weber (1999): "Humps and Bumps in Lifetime Consumption," Journal of Business and Economic Statistics, $17,22-35$.

Attanasio, O., and M. Browning (1995): "Consumption over the Life Cycle and over the Business Cycle," American Economic Review, 85(5), 1118-1137.

Bell, B. D., and J. Van Reenen (2013): "Extreme Wage Inequality: Pay at the Very Top," American Economic Review: Papers and Proceedings, 103(3), 153-57.

Bertrand, M., And A. Morse (2013): "Trickle-Down Consumption," NBER Working Paper, 18883.

Blanchflower, D., And A. Oswald (2004): "Well-being over Time in Britain and the USA," Journal of Public Economics, 88, 1359-1386.

Blundell, R., And B. Etheridge (2010): "Consumption, Income and Earnings Inequality in the UK," Review of Economic Dynamics, 13, 76-102.

Bound, J., D. A. Jaeger, And R. M. Baker (1995): "Problems with Instrumental Variables Estimation when the Correlation between the Instruments and the Endogenous Explanatory Variable is Weak," Journal of the American Statistical Association, 90(430), 443-450.

Browning, M., P.-A. Chiappori, And Y. Weiss (2014): Economics of the Family. Cambridge University Press.

Card, D., A. Mas, E. Moretti, and E. Saez (2012): "Inequality at Work: The Effect of Peer Salaries on Job Satisfaction," American Economic Review, 102(6), 2981-3003.

Chiappori, P.-A., And M. PAiella (2011): "Relative Risk Aversion Is Constant: Evidence From Panel Data," Journal of the European Economic Association, 9(6), 1021-1052. 
Clark, A., and C. Senik (2010): "Who Compares to Whom? The Anatomy of Income Comparisons in Europe," Economic Journal, 120, 573-594.

De Giorgi, G., A. Frederiksen, and L. Pistaferri (2012): "Consumption Network Effects," Working Paper.

Disney, R., J. Gathergood, And A. Henley (2010): "House Price Shocks, Negative Equity and Household Consumption in the United Kingdom," Journal of the European Economics Association, 8(6), 1179-1207.

Duesenberry, J. (1949): Income, Saving, and the Theory of Consumer Behavior. Harvard University Press.

Dynan, K. (2000): "Habit Formation in Consumer Preferences: Evidence from Panel Data," American Economic Review, 90(3), 391-406.

EAsterlin, R. (1974): "Does Economic Growth Improve the Human Lot? Some Empirical Evidence," in Nations and Households in Economic Growth: Essays in Honor of Moses Abramowitz, ed. by P. A. David, and M. W. Reder, pp. 89-125. Academic Press.

Etheridge, B. (2012): "A Test of the Household Income Process Using Consumption Data," Working Paper.

Ferrer-i Carbonell, A. (2005): "Income and Well-being: An Empirical Analysis of the Comparison Income Effect," Journal of Public Economics, 89, 997-1019.

Flores-Lagunes, A. (2007): "Finite Sample Evidence of IV Estimators under Weak Instruments," Journal of Applied Econometrics, 22, 677-94.

Frank, R. (1985): "The Demand for Unobservable and Other Nonpositional Goods," American Economic Review, 75(1), 101-116.

Frank, R. H., O. DiJk, And A. S. Levine (2010): "Expenditure Cascades," Working Paper.

Galí, J. (1994): "Keeping Up with the Joneses: Consumption Externalities, Portfolio Choice, and Asset Prices," Journal of Money, Credit and Banking, 26(1), 1-8. 
Guariglia, A., And M. Rossi (2002): "Consumption, Habit Formation, and Precautionary Saving: Evidence from the British Household Panel Survey," Oxford Economic Papers, 1, 1-19.

Hall, R., And F. Mishkin (1982): "The Sensitivity of Consumption to Transitory Income," Econometrica, 50(2), 461-481.

Hansen, L. P. (1982): "Large Sample Properties of Generalized Method of Moments Estimators," Econometrica, 50(4), 1029-1054.

Heffetz, O. (2011): "A Test of Conspicuous Consumption," The Review of Economics and Statistics, 93(4), 1101-1117.

Hopkins, E. (2008): "Inequality, Happiness and Relative Concerns: What actually is their Relationship?," Journal of Economic Inequality, 6, 351-372.

Jenkins, S. P. (2010): "The British Household Panel Survey and its Income Data," IZA Discussion Paper Series, 5242.

Kapteyn, A., S. Van de Geer, H. Van de Stadt, and T. Wansbeek (1997): "Interdependent Preferences: An Econometric Analysis," Journal of Applied Econometrics, 12(6), 665-686.

Kuhn, P., P. Kooreman, A. Soetevent, and A. Kapteyn (2011): "The Effects of Lottery Prizes on Winners and Their Neighbors: Evidence from the Dutch Postcode Lottery," American Economic Review, 101, 2226-2247.

Lewbel, A., S. Norris, and K. Pendakur (2013): "Necessary Luxuries," Working Paper.

LutTmer, E. (2005): "Neighbors as Negatives: Relative Earnings and Well-being," Quarterly Journal of Economics, 120, 963-1002.

Mankiw, N., And S. Zeldes (1991): "The Consumption of Stockholders and Nonstockholders," Journal of Financial Economics, 29, 97-112.

Manski, C. (1993): "Identification of Endogenous Social Effects: The Reflection Problem," Review of Economic Studies, 60, 531-542. 
Maurer, J., And A. Meier (2008): "Smooth it like the 'Joneses'? Estimating Peer-Group Effects in Intertemporal Consumption Choice," Economic Journal, $118,454-476$.

Moav, O., And Z. NeEman (2012): "Saving Rates and Poverty: The Role of Conspicuous Consumption and Human Capital," Economic Journal, 122(563), 933-956.

Muellbauer, J. (1988): "Habits, Rationality and Myopia in the Life Cycle Consumption Function," Annales d'Economie et de Statistique, (9), 47-70.

Pagan, A. (1984): "Econometric Issues in the Analysis of Regressions with Generated Regressors," International Economic Review, 25(1), 221-247.

Piketty, T. (2014): Capital in the Twenty-First Century. The Belknap Press of Harvard University Press.

Quintana-Domeque, C., And F. Turino (2013): "Relative Concerns on Visible Consumption: A Source of Economic Distortions," Working Paper.

Rajan, R. (2010): Fault Lines: How Hidden Fractures Still Threaten the World Economy. Princeton University Press.

Ravina, E. (2007): "Habit Persistence and Keeping Up with the Joneses: Evidence from Micro Data," Working Paper.

Runkle, D. (1991): "Liquidity Constraints and the Permanent-Income Hypothesis," Journal of Monetary Economics, 27, 73-98.

SAnderson, E., And F. WindmeiJer (2013): "A Weak Instrument F-test in Linear IV Models with Multiple Endogenous Variables," cemmap Working Paper, 58(13).

SENIK, C. (2009): "Direct Evidence on Income Comparisons and their Welfare Effects," Journal of Economic Behavior and Organization, 72, 408-424.

SheA, J. (1994): "Should we Test the Life Cycle-Permanent Income Hypothesis with Food Consumption Data?," Economics Letters, 45, 63-68. 
Stewart, M. B. (1983): "On Least Squares Estimation when the Dependent Variable is Grouped," Review of Economic Studies, 50(3), 737-753.

Veblen, T. (1899): The Theory of the Leisure Class. The Modern Library.

Wooldridge, J. M. (2010): Econometric Analysis of Cross Section and Panel Data. The MIT Press, 2 edn.

ZeLDEs, S. (1989): "Consumption and Liquidity Constraints: An Empirical Investigation," Journal of Political Economy, 97(2), 305-346. 


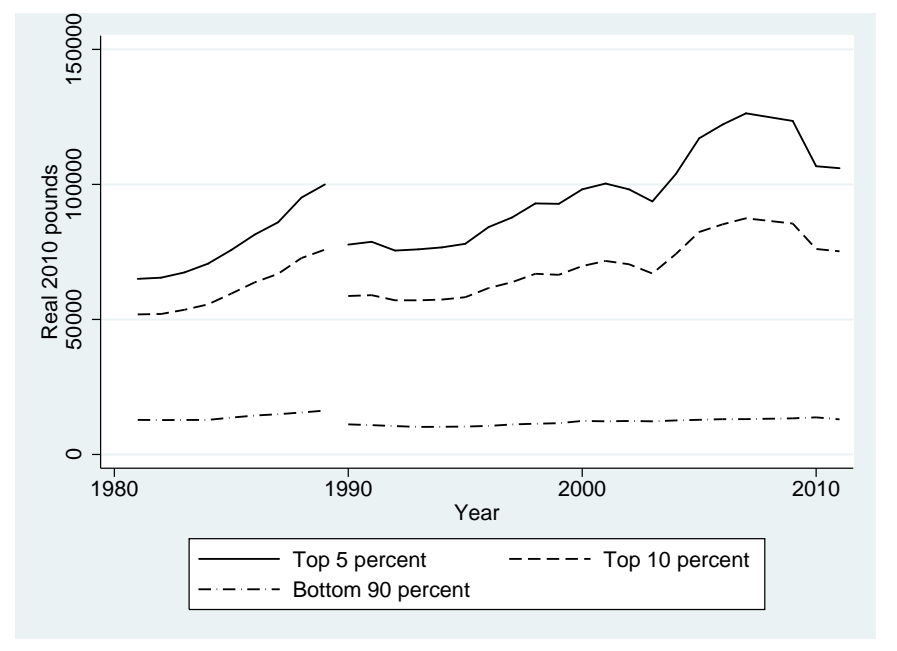

Figure 1: Average income of different income classes in the UK 1981-2011

Source: World Top Income Database. Figures until 1989 refer to average gross income of married couples and single adults. Figures from 1990 refer to the average gross income among adults (in line with the change in the tax unit).
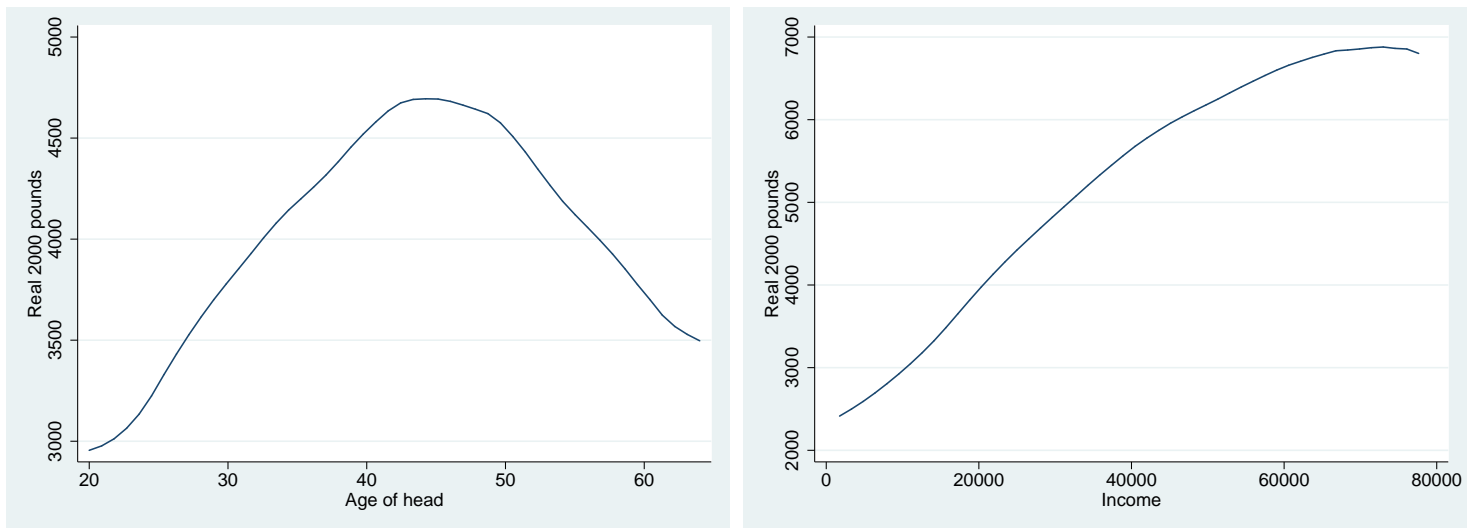

(a) Yearly food consumption on age of the (b) Yearly food consumption on net total head of household household income

Figure 2: Characteristics of total food consumption

Source: BHPS, 1997-2008. Kernel-weighted polynomial regressions of total food consumption on age and on net total household income using an Epanechnikov kernel. The bandwidth is 1.5 for age and 5000 for income. The sample includes all English, Scottish and Welsh households whose head is aged 20-64 that completed a full interview, having removed the top and bottom 1 percent of the distribution of net disposable household income. 


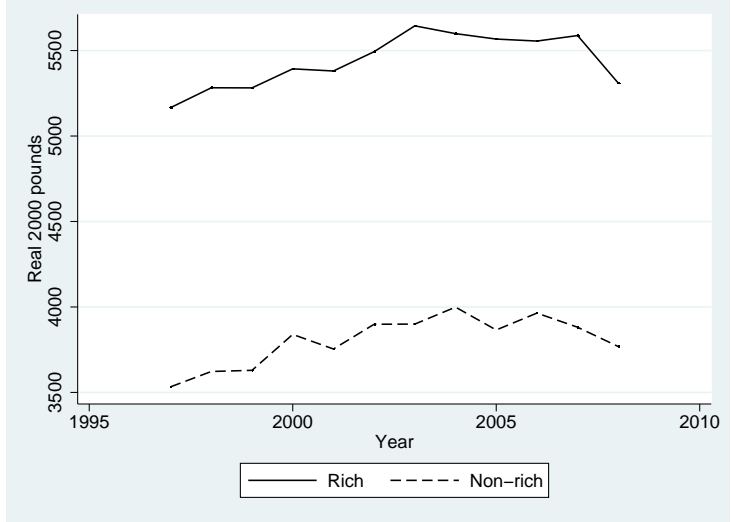

(a) Average yearly food consumption of rich and non-rich households

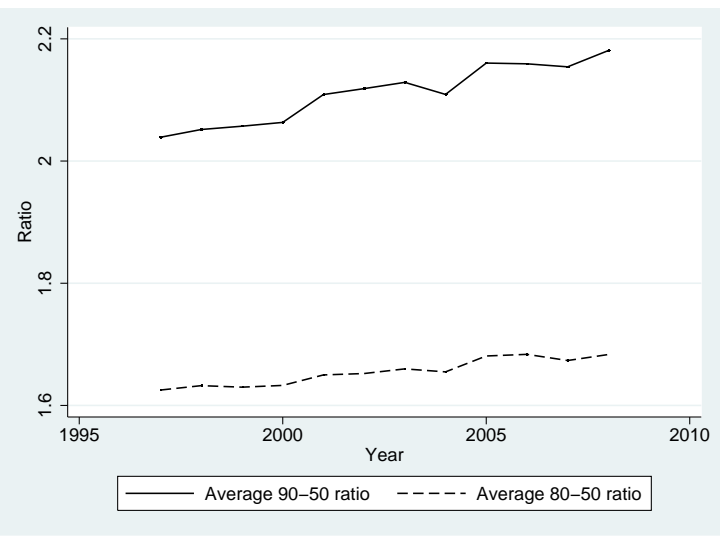

(b) Labour earnings inequality at the county level

Figure 3: Consumption and earnings inequality

Source: BHPS and ASHE, 1997-2008. Figure a) plots average consumption among rich households (above the 80th percentile) and among non-rich households (below the 80th percentile) against year. Figure b) plots the average 90/50-ratio and the average 80/50-ratio of the county-level distributions of gross earnings from paid employment against year. The sample is the study sample of county-year cells containing at least 10 households that are classified as rich. Figures are computed using the BHPS sampling weights.

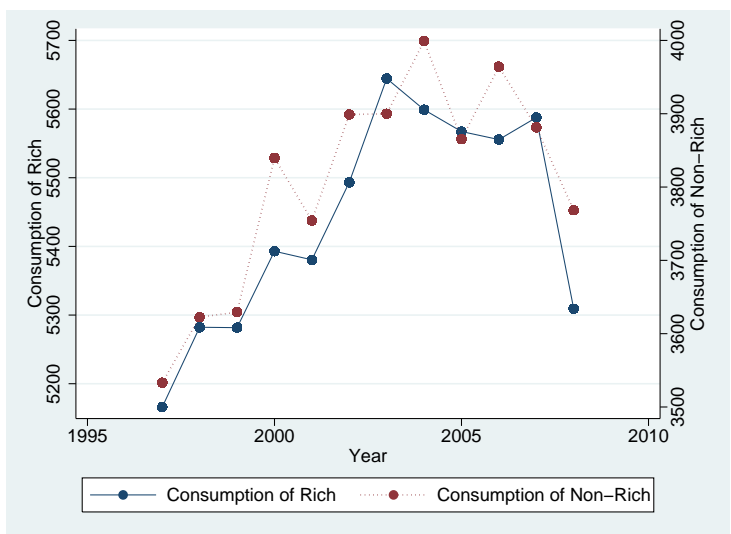

(a) Average yearly food consumption of rich and non-rich households

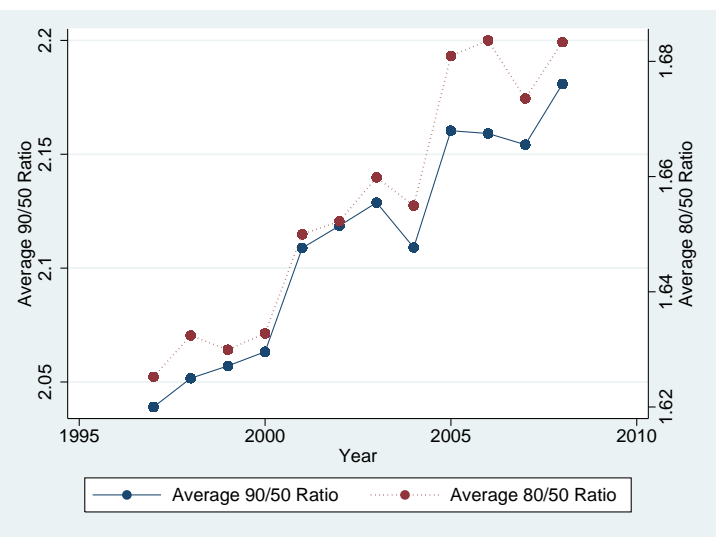

(b) Labour earnings inequality at the county level

Figure 4: Consumption and earnings inequality (different scales)

Source: BHPS and ASHE, 1997-2008. Figure a) plots average consumption among rich households (above the 80th percentile) and among non-rich households (below the 80 th percentile) against year. Figure b) plots the average $90 / 50$-ratio and the average 80/50-ratio of the county-level distributions of gross earnings from paid employment against year. The sample is the study sample of county-year cells containing at least 10 households that are classified as rich. Figures are computed using the BHPS sampling weights. 
Table 1: Euler equation: Summary statistics

\begin{tabular}{|c|c|c|c|c|}
\hline Variable & Mean & Std. dev. & Min & $\operatorname{Max}$ \\
\hline$\hat{C}$ & $3,870.79$ & $1,945.33$ & 212.641 & $14,218.59$ \\
\hline$\hat{c}$ & 8.121 & 0.565 & 5.360 & 9.562 \\
\hline$\Delta \hat{c}$ & 0.008 & 0.339 & -2.693 & 2.130 \\
\hline$Y$ & $19,526.67$ & $9,899.47$ & 821.08 & $82,852.13$ \\
\hline MainEarnings & $14,141.98$ & $8,555.02$ & 0 & $39,987.07$ \\
\hline Age & 43.891 & 11.239 & 20 & 64 \\
\hline Female & 0.306 & 0.461 & 0 & 1 \\
\hline nadults & 1.869 & 0.806 & 1 & 6 \\
\hline nchildren & 0.627 & 0.952 & 0 & 7 \\
\hline Married & 0.465 & 0.499 & 0 & 1 \\
\hline$G C S E$ & 0.361 & 0.480 & 0 & 1 \\
\hline ALevel & 0.227 & 0.419 & 0 & 1 \\
\hline AboveALevel & 0.180 & 0.385 & 0 & 1 \\
\hline PaidEmployed & 0.719 & 0.450 & 0 & 1 \\
\hline SelfEmployed & 0.123 & 0.329 & 0 & 1 \\
\hline Spouse Employed & 0.427 & 0.495 & 0 & 1 \\
\hline England & 0.895 & 0.307 & 0 & 1 \\
\hline Scotland & 0.073 & 0.260 & 0 & 1 \\
\hline Wales & 0.032 & 0.176 & 0 & 1 \\
\hline $\ln (80$ thPercentile $)$ & 10.220 & 0.153 & 9.918 & 10.597 \\
\hline Number of rich observations per cell & 21.946 & 10.348 & 10 & 52 \\
\hline$\overline{\hat{c}}^{R}$ & 8.525 & 0.101 & 8.135 & 8.831 \\
\hline$\Delta \overline{\hat{c}}^{R}$ & 0.005 & 0.083 & -0.285 & 0.361 \\
\hline $\bar{y}^{R}$ & 10.503 & 0.138 & 10.046 & 10.846 \\
\hline $\mathrm{N}$ & 13,490 & & & \\
\hline $\mathrm{N}$ first differences & 10,037 & & & \\
\hline $\mathrm{N}$ households & 2,914 & & & \\
\hline $\mathrm{N}$ counties & 50 & & & \\
\hline
\end{tabular}

Sample period: 1997-2008. All monetary variables are deflated to 2000 prices using the overall CPI and the two components for food consumption. ^ denotes observed. Definition of variables: $\hat{C}$ is the total household food consumption (it includes both food consumed at home and at restaurants) of households classified as non-rich (below the 80 th percentile); $\hat{c}$ is the $\log$ of $\hat{C} ; \Delta \hat{c}$ is the change (first-difference) in $\hat{c} ; Y$ is the current household net disposable income (sum of labour income, investment income, pension income and benefit income of all household members after taxes, National insurance contributions and other deductions) of households classified as non-rich; $\bar{c}^{R}$ is the average log consumption of food among households classified as rich (above the 80th percentile); $\Delta \overline{\hat{c}}^{R}$ is the change (first-difference) in $\overline{\hat{c}}^{R} ; \bar{y}^{R}$ is the average log of current household net disposable income among rich households. Summary statistics are computed using the BHPS sampling weights. 


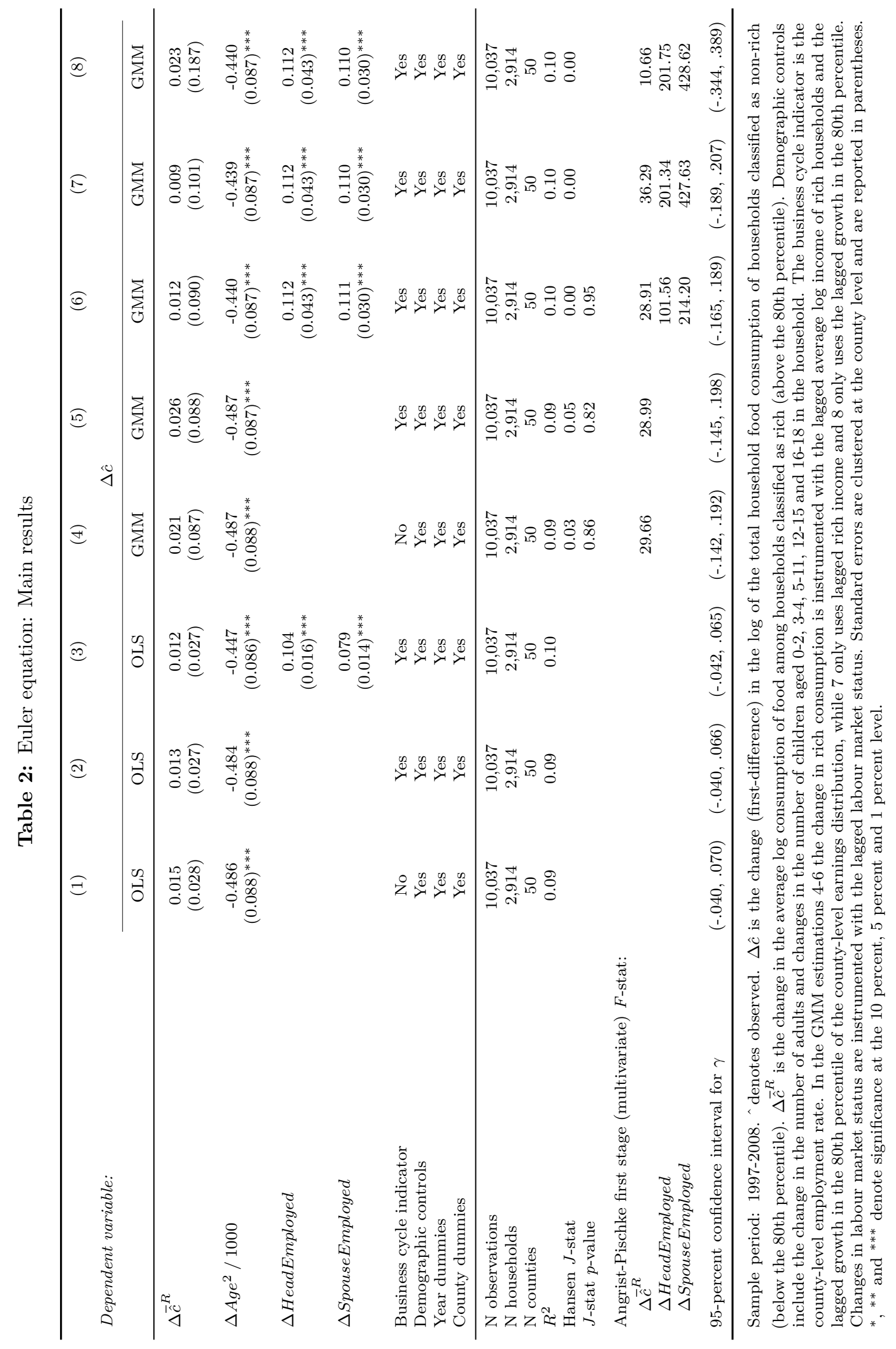


Table 3: Euler equation: Alternative definitions of reference groups

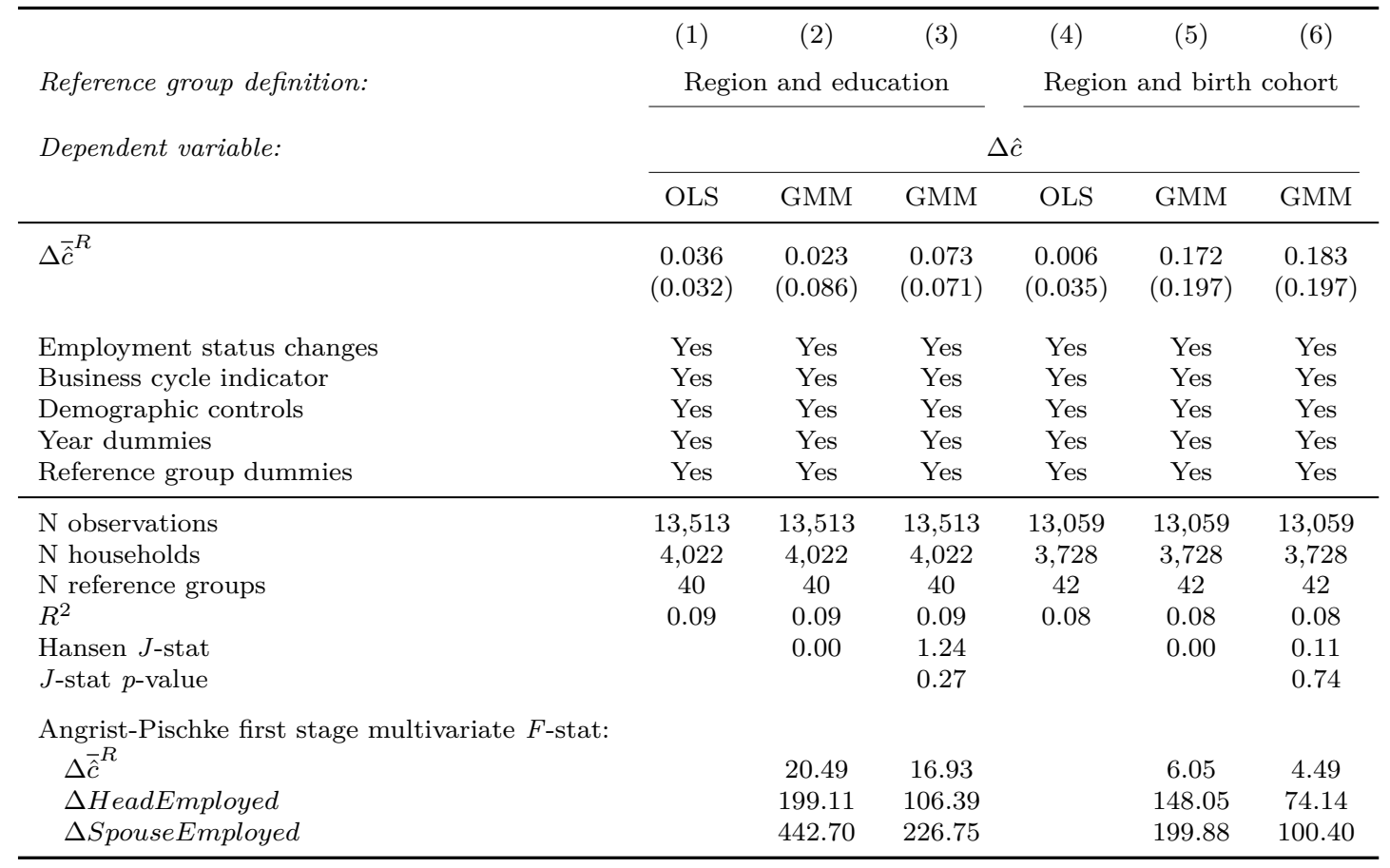

Sample period: 1997-2008. ^ denotes observed. The study sample includes only non-rich observations (below the 80th percentile) in their region-education-year cell (columns 1-3) or region-cohort-year cell (columns 4-6). $\Delta \hat{c}$ is the change (first-difference) in the log of the total household food consumption of households classified as non-rich (below the 80th percentile). $\Delta \bar{c}^{R}$ is the change in the average log consumption of food among households classified as rich (above the 80th percentile) in a given cell. In the GMM estimations 2 and 5 the change in rich consumption is instrumented with the lagged average log income of rich households. Columns 3 and 6 add the lagged change in the fraction of spouses employed in the rich group. Changes in labour market status are instrumented with the lagged labour market status. Standard errors are clustered at the reference group level and are reported in parentheses. * ** and *** denote significance at the 10 percent, 5 percent and 1 percent level. 
Table 4: Euler equation: Exogenous effects

\begin{tabular}{|c|c|c|c|c|c|c|}
\hline \multirow{3}{*}{ Dependent variable: } & (1) & $(2)$ & $(3)$ & $(4)$ & $(5)$ & $(6)$ \\
\hline & \multicolumn{6}{|c|}{$\Delta \hat{c}$} \\
\hline & OLS & OLS & OLS & GMM & GMM & GMM \\
\hline$\Delta \overline{\hat{c}}^{R}$ & $\begin{array}{c}0.013 \\
(0.027)\end{array}$ & $\begin{array}{c}0.045 \\
(0.044)\end{array}$ & $\begin{array}{c}0.042 \\
(0.049)\end{array}$ & $\begin{array}{c}0.065 \\
(0.190)\end{array}$ & $\begin{array}{c}0.075 \\
(0.225)\end{array}$ & $\begin{array}{c}0.075 \\
(0.228)\end{array}$ \\
\hline$\Delta \overline{A g e}^{R}$ & & $\begin{array}{c}0.000 \\
(0.002)\end{array}$ & $\begin{array}{c}0.000 \\
(0.002)\end{array}$ & & $\begin{array}{l}-0.000 \\
(0.003)\end{array}$ & $\begin{array}{l}-0.000 \\
(0.003)\end{array}$ \\
\hline$\Delta \overline{\text { nadults }}^{R}$ & & $\begin{array}{c}-0.056 \\
(0.033)^{*}\end{array}$ & $\begin{array}{c}-0.058 \\
(0.032)^{*}\end{array}$ & & $\begin{array}{l}-0.063 \\
(0.060)\end{array}$ & $\begin{array}{l}-0.063 \\
(0.071)\end{array}$ \\
\hline$\Delta \overline{\text { nchildren }}^{R}$ & & $\begin{array}{c}0.013 \\
(0.021)\end{array}$ & $\begin{array}{c}0.013 \\
(0.021)\end{array}$ & & $\begin{array}{c}0.010 \\
(0.034)\end{array}$ & $\begin{array}{c}0.010 \\
(0.034)\end{array}$ \\
\hline$\Delta \bar{y}^{R}$ & & & $\begin{array}{c}0.013 \\
(0.046)\end{array}$ & & & $\begin{array}{l}-0.000 \\
(0.216)\end{array}$ \\
\hline \multirow{4}{*}{$\begin{array}{l}\text { Business cycle indicator } \\
\text { Demographic controls } \\
\text { Year dummies } \\
\text { County dummies }\end{array}$} & Yes & Yes & Yes & Yes & Yes & Yes \\
\hline & Yes & Yes & Yes & Yes & Yes & Yes \\
\hline & Yes & Yes & Yes & Yes & Yes & Yes \\
\hline & Yes & Yes & Yes & Yes & Yes & Yes \\
\hline \multirow{5}{*}{$\begin{array}{l}\mathrm{N} \text { observations } \\
\mathrm{N} \text { households } \\
\mathrm{N} \text { counties } \\
R^{2} \\
\text { Hansen } J \text {-stat }\end{array}$} & 10,037 & 10,037 & 10,037 & 10,037 & 10,037 & 10,037 \\
\hline & 2,914 & 2,914 & 2,914 & 2,914 & 2,914 & 2,914 \\
\hline & 50 & 50 & 50 & 50 & 50 & 50 \\
\hline & 0.09 & 0.09 & 0.09 & 0.09 & 0.09 & 0.09 \\
\hline & & & & 0.00 & 0.00 & 0.00 \\
\hline \multicolumn{7}{|c|}{ Angrist-Pischke first stage (multivariate) $F$-stat: } \\
\hline \multicolumn{2}{|l|}{$\Delta \overline{\hat{c}}^{R}$} & & & 10.66 & 14.62 & 11.53 \\
\hline$\Delta \bar{y}^{R}$ & & & & & & 15.21 \\
\hline
\end{tabular}

Sample period: 1997-2008. ^denotes observed. $\Delta \hat{c}$ is the change (first-difference) in the log of the total household food consumption of households classified as non-rich (below the 80th percentile). $\Delta \overline{\hat{c}}^{R}$ is the change in the average log consumption of food among households classified as rich (above the 80th percentile). In the GMM estimations the change in rich consumption is instrumented with the lagged growth in the 80th percentile of the county-level earnings distribution. In column 6 the change in rich income is instrumented with lagged average total family hours worked among rich households. Standard errors are clustered at the county level and are reported in parentheses. ${ }^{*}, * *$ and ${ }^{* * *}$ denote significance at the 10 percent, 5 percent and 1 percent level. 
Table 5: Euler equation: Households with positive current investment income

\begin{tabular}{|c|c|c|c|c|c|c|}
\hline \multirow{3}{*}{ Dependent variable: } & (1) & (2) & (3) & (4) & (5) & (6) \\
\hline & \multicolumn{6}{|c|}{$\Delta \hat{c}$} \\
\hline & OLS & OLS & OLS & GMM & GMM & GMM \\
\hline$\Delta \overline{\hat{c}}^{-R}$ & $\begin{array}{c}0.068 \\
(0.043)\end{array}$ & $\begin{array}{c}0.067 \\
(0.043)\end{array}$ & $\begin{array}{c}0.069 \\
(0.044)\end{array}$ & $\begin{array}{c}0.067 \\
(0.148)\end{array}$ & $\begin{array}{c}0.070 \\
(0.148)\end{array}$ & $\begin{array}{c}0.050 \\
(0.142)\end{array}$ \\
\hline$\Delta$ HeadEmployed & & & $\begin{array}{c}0.034 \\
(0.021)\end{array}$ & & & $\begin{array}{c}0.023 \\
(0.064)\end{array}$ \\
\hline$\Delta$ SpouseEmployed & & & $\begin{array}{c}0.078 \\
(0.021)^{* * *}\end{array}$ & & & $\begin{array}{c}0.136 \\
(0.049)^{* * *}\end{array}$ \\
\hline Business cycle indicator & No & Yes & Yes & No & Yes & Yes \\
\hline Demographic controls & Yes & Yes & Yes & Yes & Yes & Yes \\
\hline Year dummies & Yes & Yes & Yes & Yes & Yes & Yes \\
\hline County dummies & Yes & Yes & Yes & Yes & Yes & Yes \\
\hline $\mathrm{N}$ observations & 4,105 & 4,105 & 4,105 & 4,105 & 4,105 & 4,105 \\
\hline $\mathrm{N}$ households & 1,555 & 1,555 & 1,555 & 1,555 & 1,555 & 1,555 \\
\hline $\mathrm{N}$ counties & 50 & 50 & 50 & 50 & 50 & 50 \\
\hline$R^{2}$ & 0.11 & 0.11 & 0.12 & 0.11 & 0.11 & 0.11 \\
\hline Hansen $J$-stat & & & & 1.57 & 1.65 & 1.34 \\
\hline$J$-stat $p$-value & & & & 0.21 & 0.20 & 0.25 \\
\hline Angrist-Pischke first stą & & & & & & \\
\hline$\Delta \overline{\hat{c}}^{R}$ & & & & 28.47 & 28.23 & 28.35 \\
\hline$\Delta$ HeadEmployed & & & & & & 25.84 \\
\hline$\Delta$ SpouseEmployed & & & & & & 109.19 \\
\hline
\end{tabular}

Sample period: 1997-2008. ^ denotes observed. $\Delta \hat{c}$ is the change (first-difference) in the log of the total household food consumption of households classified as non-rich (below the 80th percentile). $\Delta \overline{\hat{c}}^{R}$ is the change in the average log consumption of food among households classified as rich (above the 80th percentile). In the GMM estimations the change in rich consumption is instrumented with the lagged average log income of rich households and the lagged growth in the 80th percentile of the county-level earnings distribution. Changes in labour market status are instrumented with the lagged labour market status. Standard errors are clustered at the county level and are reported in parentheses. ${ }^{*}, * *$ and ${ }^{* * *}$ denote significance at the 10 percent, 5 percent and 1 percent level. 
Table 6: Euler equation: Interval regression results

\begin{tabular}{|c|c|c|c|c|c|c|}
\hline \multirow{3}{*}{ Dependent variable: } & (1) & (2) & (3) & (4) & (5) & (6) \\
\hline & \multicolumn{6}{|c|}{$\Delta \hat{c}$} \\
\hline & OLS & OLS & OLS & INTREG & INTREG & INTREG \\
\hline$\Delta \overline{\hat{c}}^{R}$ & $\begin{array}{c}0.017 \\
(0.029)\end{array}$ & $\begin{array}{c}0.015 \\
(0.028)\end{array}$ & $\begin{array}{c}0.015 \\
(0.028)\end{array}$ & $\begin{array}{c}0.038 \\
(0.028)\end{array}$ & $\begin{array}{c}0.036 \\
(0.027)\end{array}$ & $\begin{array}{c}0.036 \\
(0.027)\end{array}$ \\
\hline$\Delta A g e^{2} / 1000$ & $\begin{array}{c}-0.500 \\
(0.090)^{* * *}\end{array}$ & $\begin{array}{c}-0.499 \\
(0.090)^{* * *}\end{array}$ & $\begin{array}{c}-0.459 \\
(0.088)^{* * *}\end{array}$ & $\begin{array}{c}-0.509 \\
(0.095)^{* * *}\end{array}$ & $\begin{array}{c}-0.508 \\
(0.095)^{* * *}\end{array}$ & $\begin{array}{c}-0.468 \\
(0.093)^{* * *}\end{array}$ \\
\hline$\Delta$ HeadEmployed & & & $\begin{array}{c}0.105 \\
(0.016)^{* * *}\end{array}$ & & & $\begin{array}{c}0.104 \\
(0.015)^{* * *}\end{array}$ \\
\hline$\Delta$ SpouseEmployed & & & $\begin{array}{c}0.080 \\
(0.014)^{* * *}\end{array}$ & & & $\begin{array}{c}0.076 \\
(0.014)^{* * *}\end{array}$ \\
\hline Business cycle indicator & No & Yes & Yes & No & Yes & Yes \\
\hline Demographic controls & Yes & Yes & Yes & Yes & Yes & Yes \\
\hline Year dummies & Yes & Yes & Yes & Yes & Yes & Yes \\
\hline County dummies & Yes & Yes & Yes & Yes & Yes & Yes \\
\hline $\mathrm{N}$ observations & 9,826 & 9,826 & 9,826 & 9,826 & 9,826 & 9,826 \\
\hline $\mathrm{N}$ households & 2,873 & 2,873 & 2,873 & 2,873 & 2,873 & 2,873 \\
\hline $\mathrm{N}$ counties & 50 & 50 & 50 & 50 & 50 & 50 \\
\hline & 0.09 & 0.09 & 0.10 & & & \\
\hline Log pseudolikelihood & & & & -8778.9614 & -8778.6522 & -8735.9402 \\
\hline \multicolumn{7}{|c|}{$\begin{array}{l}\text { Sample period: } 1997-2008 .{ }^{\wedge} \text { denotes observed. } \Delta \hat{c} \text { is the change (first-difference) in the log of the total } \\
\text { household food consumption of households classified as non-rich (below the } 80 \text { th percentile). } \Delta \overline{\hat{c}}{ }^{R} \text { is the } \\
\text { change in the average log consumption of food among households classified as rich (above the } 80 \text { th percentile). } \\
\text { In the interval regressions } 4-6 \text { the interval for the dependent variable for each observation is bounded by the } \\
\text { minimum and maximum possible consumption growth according to the bins. Standard errors are clustered } \\
\text { at the county level and are reported in parentheses. }{ }^{*},{ }^{* *} \text { and }{ }^{* * *} \text { denote significance at the } 10 \text { percent, } 5 \\
\text { percent and } 1 \text { percent level. }\end{array}$} \\
\hline
\end{tabular}


Table 7: Euler equation: Heterogeneous relative concerns

\begin{tabular}{|c|c|c|c|c|c|c|}
\hline \multirow{3}{*}{ Dependent variable: } & (1) & $(2)$ & (3) & (4) & $(5)$ & (6) \\
\hline & \multicolumn{6}{|c|}{$\Delta \hat{c}$} \\
\hline & OLS & OLS & OLS & OLS & OLS & OLS \\
\hline$\Delta \overline{\hat{c}}^{R}$ & $\begin{array}{l}-0.018 \\
(0.032)\end{array}$ & $\begin{array}{c}0.086 \\
(0.040)^{* *}\end{array}$ & $\begin{array}{c}0.008 \\
(0.057)\end{array}$ & $\begin{array}{c}-0.021 \\
(0.056)\end{array}$ & $\begin{array}{c}-0.055 \\
(0.042)\end{array}$ & $\begin{array}{l}-0.003 \\
(0.047)\end{array}$ \\
\hline$\Delta \overline{\hat{c}}^{R} \times$ LowIneq & $\begin{array}{c}0.104 \\
(0.060)^{*}\end{array}$ & & & & & \\
\hline$\Delta \overline{\hat{c}}^{R} \times$ LowDens & & $\begin{array}{c}-0.128 \\
(0.057)^{* *}\end{array}$ & & & & \\
\hline$\Delta \overline{\hat{c}}^{R} \times$ Old & & & $\begin{array}{c}0.010 \\
(0.097)\end{array}$ & & & \\
\hline Old & & & $\begin{array}{l}-0.001 \\
(0.010)\end{array}$ & & & \\
\hline$\Delta \overline{\hat{c}}^{R} \times$ Married $_{-1}$ & & & & $\begin{array}{c}0.077 \\
(0.082)\end{array}$ & & \\
\hline Married $_{-1}$ & & & & $\begin{array}{c}-0.010 \\
(0.004)^{* *}\end{array}$ & & \\
\hline$\Delta \overline{\hat{c}}^{R} \times L_{o w E d u c_{-1}}$ & & & & & $\begin{array}{c}0.114 \\
(0.069)^{*}\end{array}$ & \\
\hline LowEduc -1 & & & & & $\begin{array}{c}-0.005 \\
(0.003)^{*}\end{array}$ & \\
\hline$\Delta \overline{\hat{c}}^{R} \times$ MiddleInc-1 & & & & & & $\begin{array}{c}0.037 \\
(0.067)\end{array}$ \\
\hline MiddleInc-1 & & & & & & $\begin{array}{c}-0.009 \\
(0.005)^{*}\end{array}$ \\
\hline Employment status changes & Yes & Yes & Yes & Yes & Yes & Yes \\
\hline Business cycle indicator & Yes & Yes & Yes & Yes & Yes & Yes \\
\hline Demographic controls & Yes & Yes & Yes & Yes & Yes & Yes \\
\hline Year dummies & Yes & Yes & Yes & Yes & Yes & Yes \\
\hline County dummies & Yes & Yes & Yes & Yes & Yes & Yes \\
\hline $\mathrm{N}$ observations & 9,618 & 10,037 & 10,037 & 10,037 & 10,037 & 10,037 \\
\hline $\mathrm{N}$ households & 2,879 & 2,914 & 2,914 & 2,914 & 2,914 & 2,914 \\
\hline $\mathrm{N}$ counties & 47 & 50 & 50 & 50 & 50 & 50 \\
\hline$R^{2}$ & 0.09 & 0.09 & 0.09 & 0.09 & 0.09 & 0.09 \\
\hline
\end{tabular}

Sample period: 1997-2008. ' denotes observed. $\Delta \hat{c}$ is the change (first-difference) in the log of the total household food consumption of households classified as non-rich (below the 80th percentile). $\Delta \overline{\hat{c}}^{R}$ is the change in the average log consumption of food among households classified as rich (above the 80th percentile). Low Ineq and LowDens are dummy variables indicating whether an observation is from a county classified as a low inequality or a low density area according to a median split of the sample along the values in 1997. These estimations do not directly control for the dummy variables because these variables do not vary within counties and we include county dummies. Old is a dummy variable indicating whether the head is aged above 42. Married is a marital status dummy and LowEduc takes a value of 1 if the educational attainment of the head is below A-Level. MiddleInc is a dummy variable indicating whether the labour earnings of the main earner exceed the 50th percentile of the earnings distribution. The controls are as explained previously. Standard errors are clustered at the county level and are reported in parentheses. ${ }^{*}, * *$ and ${ }^{* * *}$ denote significance at the 10 percent, 5 percent and 1 percent level. 


\section{A Appendix}

\section{A.1 Log-linearisation}

This section provides the details of the log-linearisation of the Euler equation:

$$
\beta E_{t-1}\left[\left(1+r_{i, t}\right) \exp \left(\Delta \psi_{i, t}\right)\left(\frac{\tilde{C}_{i, t}}{\tilde{C}_{i, t-1}}\right)^{-\rho}\right]=1
$$

Taking a log-linear approximation of the term in brackets around a steady state in which variables are either constant or grow at a constant rate gives:

$$
\begin{array}{r}
\left(1+r_{i, t}\right) \exp \left(\Delta \psi_{i, t}\right)\left(\frac{\tilde{C}_{i, t}}{\tilde{C}_{i, t-1}}\right)^{-\rho} \\
=\exp \left(\ln \left(1+r_{i, t}\right)+\Delta \psi_{i, t}-\rho \Delta \ln \tilde{C}_{i, t}\right) \\
\approx \exp \left(\ln \left(1+r_{i}^{*}\right)+\Delta \psi_{i, t}^{*}-\rho \Delta \ln \tilde{C}_{i, t}^{*}\right) \\
+\exp \left(\ln \left(1+r_{i}^{*}\right)+\Delta \psi_{i, t}^{*}-\rho \Delta \ln \tilde{C}_{i, t}^{*}\right)\left[\ln \left(1+r_{i, t}\right)-\ln \left(1+r_{i}^{*}\right)\right] \\
+\exp \left(\ln \left(1+r_{i}^{*}\right)+\Delta \psi_{i, t}^{*}-\rho \Delta \ln \tilde{C}_{i, t}^{*}\right)\left[\Delta \psi_{t}-\Delta \psi_{t}^{*}\right] \\
-\rho \exp \left(\ln \left(1+r_{i}^{*}\right)+\Delta \psi_{i, t}^{*}-\rho \Delta \ln \tilde{C}_{i, t}^{*}\right)\left[\ln \tilde{C}_{i, t}-\ln \tilde{C}_{i, t}^{*}\right] \\
+\rho \exp \left(\ln \left(1+r_{i}^{*}\right)+\Delta \psi_{i, t}^{*}-\rho \Delta \ln \tilde{C}_{i, t}^{*}\right)\left[\ln \tilde{C}_{i, t-1}-\ln \tilde{C}_{i, t-1}^{*}\right],
\end{array}
$$

where asterisks denote steady state values of the variables. Now define the constant:

$$
K=\exp \left(\ln \left(1+r_{i}^{*}\right)+\Delta \psi_{i, t}^{*}-\rho \Delta \ln \tilde{C}_{i, t}^{*}\right)
$$

Substituting the approximation back into the Euler equation (1) and ignoring the non-log-linear component of consumption growth gives:

$$
\begin{aligned}
\beta E_{t-1}[K & +K\left[\ln \left(1+r_{i, t}\right)-\ln \left(1+r_{i}^{*}\right)\right] \\
& \left.+K\left[\Delta \psi_{i, t}-\Delta \psi_{i, t}^{*}\right]-\rho K\left[\Delta \ln \tilde{C}_{i, t}-\Delta \ln \tilde{C}_{i, t}^{*}\right]\right]=1 .
\end{aligned}
$$

In steady state, the Euler equation is given by $\beta E_{t-1}[K]=1$. Taking logs gives: 


$$
\Delta \ln \tilde{C}_{i, t}^{*}=\frac{1}{\rho} \ln \beta+\frac{1}{\rho} \ln \left(1+r_{i}^{*}\right)+\frac{1}{\rho} \Delta \psi_{i}^{*}
$$

Subtracting from (2) the untransformed version of the steady state Euler equation, dividing by $\beta K$ and adding the logged version of the steady state Euler equation, one obtains:

$$
E_{t-1}\left[\Delta \ln \tilde{C}_{i, t}\right]=\frac{1}{\rho} \ln \beta+\frac{1}{\rho} E_{t-1}\left[\ln \left(1+r_{i, t}\right)\right]+\frac{1}{\rho} E_{t-1}\left[\Delta \psi_{i, t}\right]
$$

\section{A.2 Additional tables}




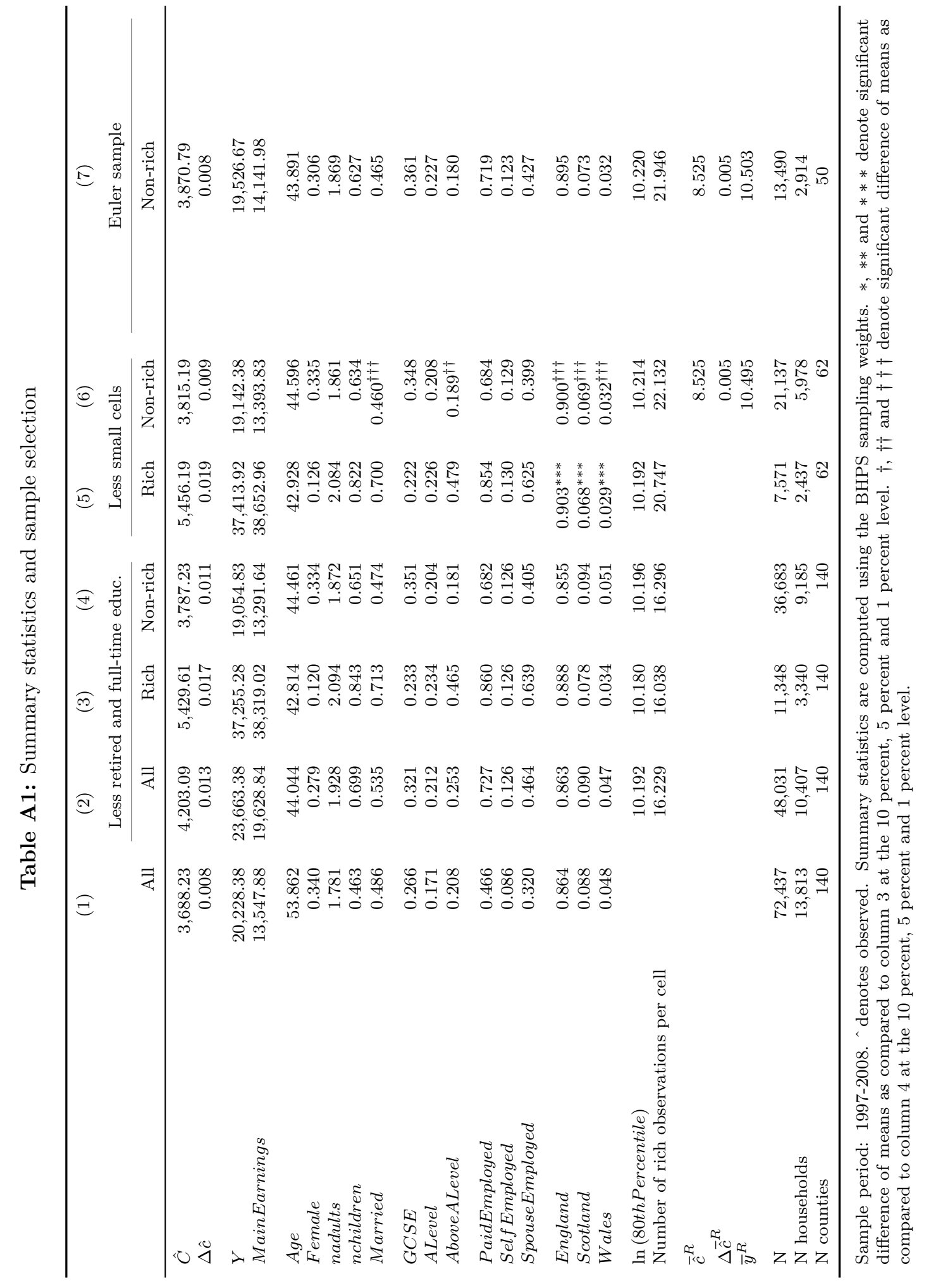




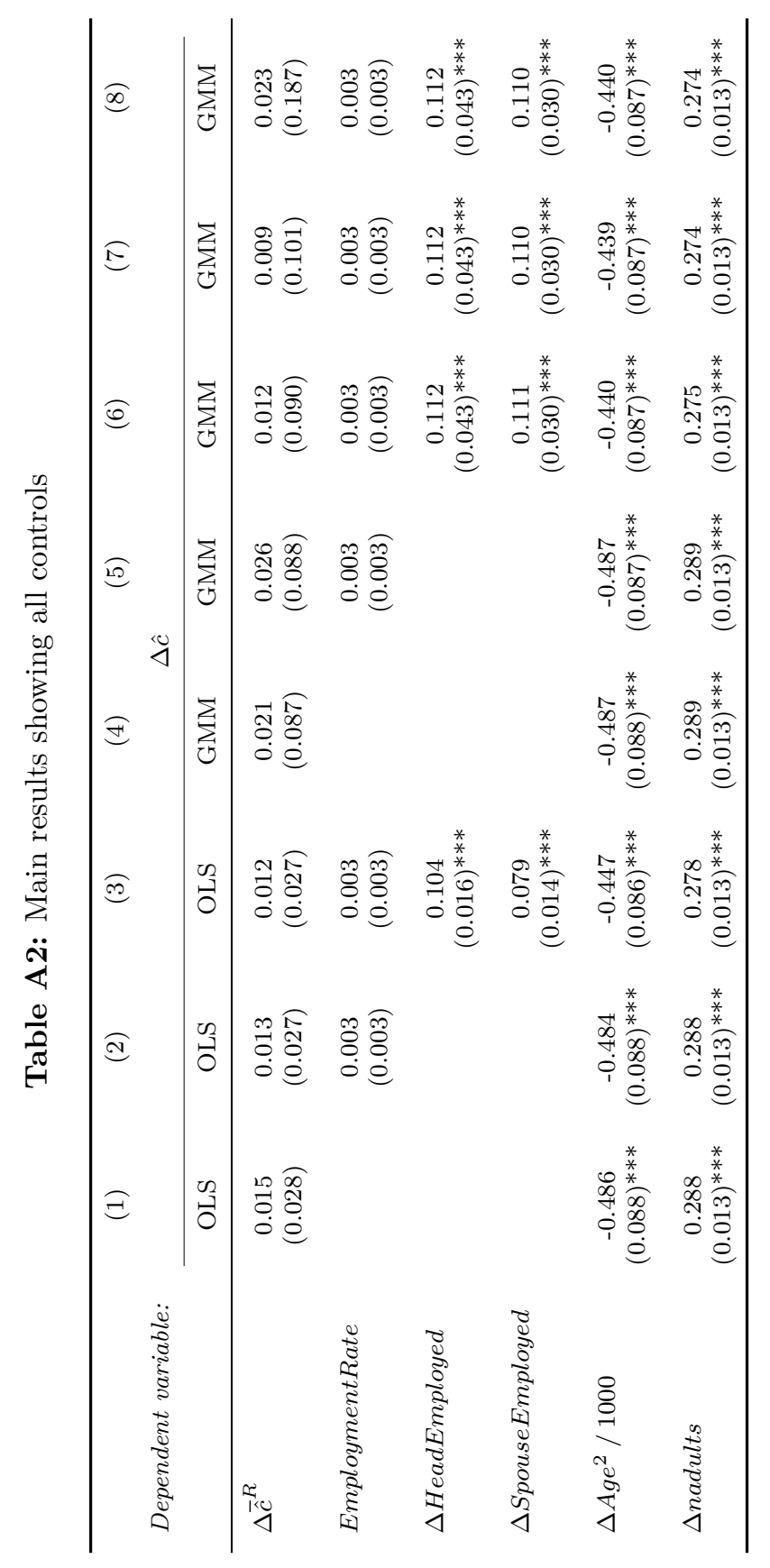




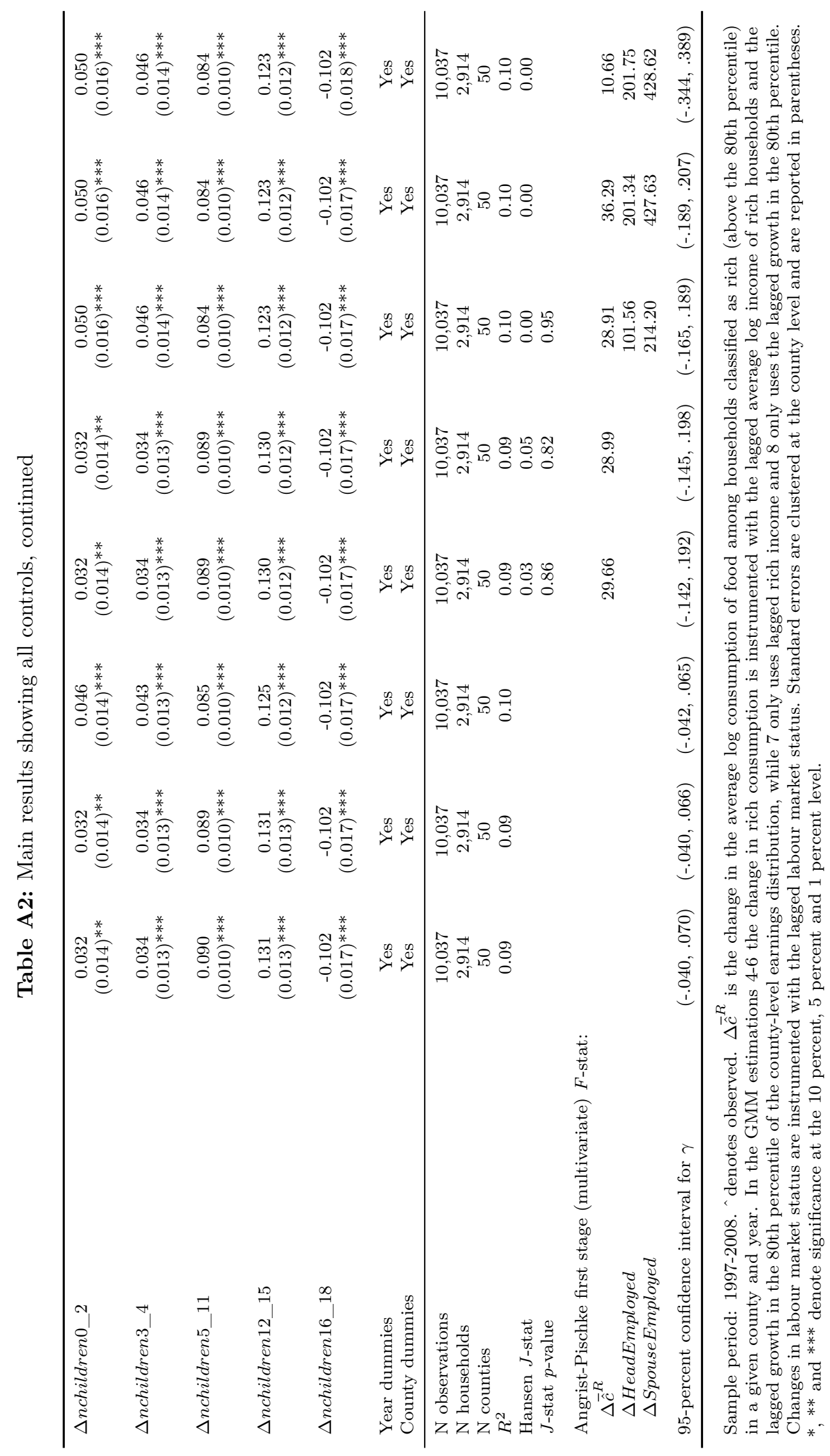




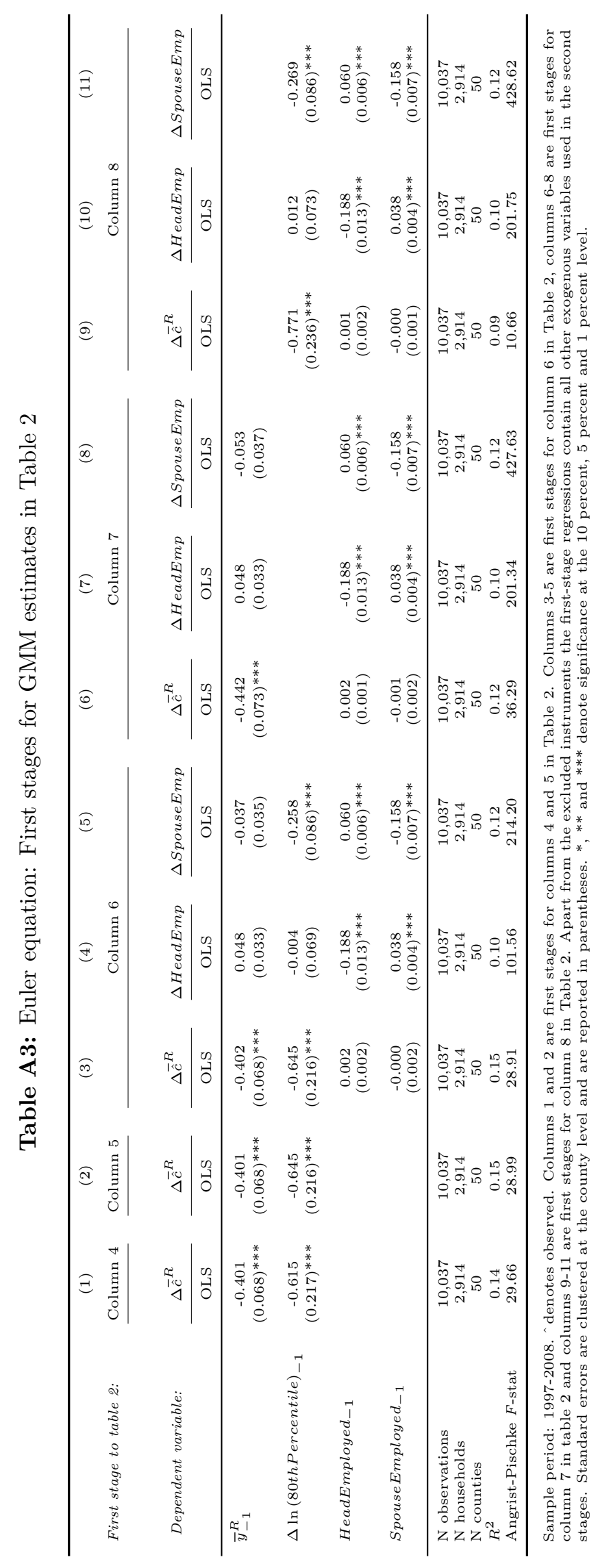

